\title{
Liberalização financeira externa: investigando alguns efeitos macroeconômicos no Brasil entre 1994 e $2006^{1}$
}

\author{
Cesar Rodrigues van der Laan ${ }^{2}$ \\ André Moreira Cunha ${ }^{3}$ \\ Marcos Tadeu Caputi Lélis ${ }^{4}$
}

\section{Resumo}

O presente estudo analisa a dinâmica da abertura da conta capital no Brasil, em curso, desde o começo dos anos 1990. São utilizados dois índices independentes como proxies para a avaliação do comportamento do setor externo da economia (ICC, de jure, IAF, de facto). Baseados na metodologia de vetores autorregressivos (VAR), as evidências vão ao encontro da perspectiva de que as ligações entre liberalização financeira, taxa de juros e crescimento econômico podem não ser tão fortes quanto o suposto pela teoria macroeconômica convencional.

Palavras-chave: Liberalização financeira; Desempenho macroeconômico; Conta de capitais; Gerenciamento externo; Brasil.

\section{Abstract \\ External financial liberalization: investigating some of the macroeconomic effects on Brazil between 1994 and 2006}

This article investigates the process of capital account liberalization that has been in place in Brazil since the early 1990s. Two independent indices are used as proxies to measure the behavior of the economy's external sector, examining both notional (ICC) and effective (IAF) financial flows to and from Brazil. Based on the vector autoregressive (VAR) method, empirical findings support the view that the links between financial liberalization and economic growth might not be as strong as supposed by mainstream macroeconomic theory.

Keywords: Financial liberalization; Macroeconomic performance; Capital account; External management; Brazil.

JEL E44, F41, F43.

\section{Introdução}

A partir dos anos 1980, especialmente, nos anos 1990, ocorreram importantes transformações que apontavam para um período de economias mais

(1) Trabalho recebido em setembro de 2007 e aprovado em novembro de 2009. As opiniões aqui expressas não refletem, necessariamente, a posição oficial das instituições de origem dos autores.

(2) Funcionário do Banco Central do Brasil (BCB), Brasília, DF, Brasil. E-mail: cesarvdl@yahoo.com.

(3) Professor do Programa de Pós-Graduação em Economia da Universidade Federal do Rio Grande do Sul (PPGE-UFRGS) / Pesquisador do CNPq (Conselho Nacional de Desenvolvimento Científico e Tecnológico), Porto Alegre, RS, Brasil. E-mail: andre.cunha@ufrgs.br.

(4) Funcionário da Apex Brasil (Agência Brasileira de Promoção de Exportações e Investimentos), Brasília, DF, Brasil. E-mail: mcaputti@uol.com.br. 
abertas. O ressurgimento dos fluxos internacionais de capitais, a partir de 1990, foi reflexo da estratégia de desenvolvimento predominante, traduzida por uma maior integração financeira e um vasto processo de desregulamentação, ocorrido tanto nos países desenvolvidos como em desenvolvimento. O Brasil acompanhou essa tendência com um processo notório de liberalização financeira que criou, em um primeiro momento, condições favoráveis aos influxos de capitais internacionais, complementado, posteriormente, pela desregulamentação mais acentuada dos fluxos de residentes a partir do ano 2000, no intuito da aceleração do crescimento econômico e da criação de uma maior estabilidade macroeconômica. Essa elevação do fluxo de capitais internacionais no período recente que se associou, entretanto, à ocorrência de crises de caráter financeiro em escala mundial despertou o interesse para várias investigações teórico-empíricas sobre o grau de exposição dos países e efeitos de maior integração global. Assim, grande parte dos trabalhos centrou-se na performance macroeconômica dos países em desenvolvimento nesse novo contexto institucional e na eficácia ou não de se controlar a movimentação do capital externo no ambiente mais globalizado. A constatação predominante na literatura empírica é a de que a liberalização financeira não foi capaz de produzir trajetórias robustas e sustentáveis de crescimento como inicialmente se esperava e, ademais, parece estar associada à instabilidade macroeconômica (Prasad et al., 2003; World Bank, 2005; Stiglitz et al., 2006).

É nesse contexto que o presente trabalho se insere. Procura-se contribuir de duas formas. Em um primeiro momento, são avaliadas as mudanças recentes na regulamentação do mercado cambial brasileiro. Dentre as alternativas metodológicas, toma-se, por base, a metodologia desenvolvida por Cardoso e Goldfajn (1997) e aplicada por Soihet (2002), construindo um índice de controle de capitais (ICC) para o período 1994-2006. Considera-se que tal esforço é necessário para consolidar a base de evidências empíricas do debate anteriormente resumido, na medida em que os exercícios supracitados limitaram-se ao período coberto por Soihet (2002). De lá para cá, a estratégia brasileira de abertura financeira "lenta e gradual" teve continuidade, o que sugere necessidade de aprofundamento das investigações. Ademais, introduz-se um segundo indicador de abertura financeira (IAF), construído em analogia aos indicadores tradicionais de abertura comercial. A partir disso, realiza-se um conjunto de exercícios econométricos com base na metodologia VAR, para verificar a relação entre o ICC e o IAF e o comportamento do crescimento da economia brasileira, da taxa de juros e taxa de câmbio. O objetivo restringe-se, portanto, aos efeitos do processo de abertura e integração financeira do País com o exterior, considerando essas variáveis macroeconômicas. Os resultados vão ao encontro das evidências predominantes na literatura recente, vale dizer, de que a globalização financeira tem pouca vinculação com o crescimento. Contrariando a hipótese de Arida 
(2003a), a ampliação da abertura financeira não parece estar vinculada a uma redução significativa na taxa de juros. À guisa de conclusão, reforça-se a necessidade de aprofundamento das investigações sobre a especificidade da estratégia brasileira de liberalização financeira de modo a compatibilizar-se os objetivos de crescimento com estabilidade.

\section{Mensuração da liberalização financeira: alternativas metodológicas e dificuldades implícitas à construção dos indicadores empíricos}

A tentativa de mensurar a liberalização da conta capital não é tarefa fácil. Como Obstfeld e Taylor (2004, p. 28) pressupõem, a assunção de que o grau de mobilidade dos capitais ou a integração dos mercados financeiros mundiais podem ser capturados por um simples parâmetro é mais propriamente um desejo do pesquisador do que uma realidade acadêmica. De fato, a mensuração da integração financeira dos mercados é um problema empírico, não existindo um critério reconhecido universalmente, nesse campo de pesquisa. Alguns trabalhos com objetivos ou objetos de pesquisa específicos optam por utilizar proxies relacionadas com o grau de abertura dos mercados de capitais. Uma prática tem sido usar dados compilados pelo International Finance Corporation e construir um índice com base nas restrições de compra de ações por não residentes. A comparação com o total de ações disponíveis indica o grau de abertura do mercado local aos investidores estrangeiros, ao apontar a fração do mercado doméstico que investidores internacionais podem legalmente deter. ${ }^{5}$

De maneira geral, as abordagens dentre os programas de pesquisa fundamentam-se em critérios de quantidades, preços ou restrições legais relacionadas aos fluxos de capitais, para a construção de proxies para a integração financeira. Todos possuem objeções. Por um lado, evidências quantitativas apresentam objeções quanto a sua capacidade de representar integração financeira, em particular, devido ao fato de que alterações na estrutura econômica nos mercados podem induzir mudanças quantitativas, sem qualquer modificação, nos custos de transação (controles de capitais) subjacentes à arbitragem. Não modifica, portanto, o verdadeiro grau de integração de uma economia aos mercados internacionais, ou seja, a variação quantitativa dos fluxos, para mais ou para menos, não, necessariamente, implica em mudanças institucionais relativas à implementação de uma maior ou menor facilidade à movimentação dos capitais entre os países. Assim, economias podem tornar-se mais ou menos integradas, independentemente, dos custos de transação (relativos a controles de capitais). É essa a diferenciação entre abertura e integração financeira: enquanto o primeiro termo refere-se à variação no arcabouço regulatório dos fluxos de capitais, o último remete aos fluxos de capitais propriamente ditos, ainda que ambos acabem

(5) Vide Edison e Warnock (2003) e Bekaert et al. (2005). 
sendo usados para se referirem ao processo mais geral da globalização dos fluxos financeiros. São, portanto, dimensões distintas, mas, ao mesmo tempo, complementares do chamado processo de globalização financeira. Um índice per se não consegue captar as duas dimensões. Do mesmo modo, o tamanho dos fluxos seria um critério frágil ou falho por supor, também, que não existam barreiras institucionais à movimentação dos fluxos ou, ao menos, por não as considerar, assumindo-as estáticas. Torna-se, assim, o reflexo de apenas uma dimensão de um processo mais amplo.

Isso apontaria para a alternativa metodológica de utilizar um índice baseado em preço. Alguns autores sugerem examinar os diferenciais de preços entre economias como indicador do grau de integração externa. Para tanto, é preciso assumir hipóteses auxiliares como a tendência de os preços serem determinados pelos mesmos fatores e com os mesmos "pesos", em diferentes economias. A igualdade de preços internacionais, entretanto, como a suposta tendência de convergência dos juros domésticos nas economias emergentes em direção ao praticado igual e hipoteticamente por todas as economias avançadas, tende, todavia, a ser apena mera probabilidade ou coincidência, não havendo nada que garanta essa hipótese (Obstfeld; Taylor, 2004). Igualdade de juros significa a inexistência de incentivo à mobilidade de capitais, de forma que nenhum fator de produção tende a se mover nessas condições, por definição. Se isso se aplica para a decisão de investimento entre diversos setores em uma economia fechada, o mesmo faz mais sentido para uma economia aberta. Nesse sentido, a convergência de preços não seria um indicador adequado à integração financeira: é a divergência de preços, como pressuposto para a arbitragem e a mobilidade de capitais entre os mercados financeiros internacionais, a condição natural característica da arquitetura financeira global. ${ }^{6}$ Ainda que a ideia de convergência de preços internacionais possa parecer mais persuasiva que o critério de quantidade, sua interpretação não é direta. É plenamente possível que todos os movimentos de preços sejam causados por mudanças estruturais no nível das economias domésticas sem correlação com mobilidade de capitais e a existência ou não de obstáculos à integração financeira externa. É bastante característica, em sistemas de metas inflacionárias, a definição exógena da taxa básica de juros por parte da autoridade monetária, o que afasta o pressuposto teórico de convergência internacional de juros. Assim, a análise da mobilidade de capitais com base em diferencial de juros acaba sendo um indicador limitado para captar um fenômeno que tem, por definição, uma origem política. A completa caracterização do fenômeno de integração financeira passa pela esfera da decisão política, o terceiro critério, justamente, o mais amplo utilizado no campo dos trabalhos empíricos.

(6) Segundo Obstfeld e Taylor (2004), o uso de diferenciais de juros reais e desvios da paridade de juros foram alternativas muito pouco informativas sobre o grau de integração financeira dos países. 
Para tanto, a maioria dos trabalhos utiliza uma medida baseada na existência ou não de regras restritivas à livre mobilidade de capitais, nos termos do Annual Report on Exchange Arrangements and Exchange Restrictions (AREAER) do Fundo Monetário Internacional (FMI), embora com diferentes nuances. Criouse, de início, um índice dicotômico sobre restrições na conta capital ( 0 ou 1$)$, posteriormente, refinado por Kaminsky e Schmukler (2003), variando entre 0 e 3 e indicando 3 estágios de completa repressão, parcial liberalização e total liberalização para espelhar diferentes graus de intensidade dos controles de capitais. Quinn (1997), porém, é quem irá construir uma medida mais detalhada para quantificar a intensidade da abertura da conta capital a ser adotada mais amplamente também, com base no próprio AREAER do FMI. ${ }^{7}$ Tanto o indicador original do FMI como o de Quinn (1997), todavia, refletiriam apenas a existência de restrições oficiais de jure sobre fluxos de capitais e não capturariam as diferenças na intensidade do uso das restrições sobre fluxos de capitais entre os países. Assim, uma das críticas aos estudos baseados nesses dados sugere que eles apenas proveriam indicadores genéricos sobre controles de capitais, não medindo a intensidade ou a real efetividade das diversas restrições específicas sobre as várias modalidades de entrada e saída de capitais.

Dessa forma, o grau real de abertura de um país não estaria espelhado na proxy das medidas de jure de cada país, espelhando muito menos a real integração financeira de um país com os mercados externos, a qual deve basear-se em uma medida de facto. ${ }^{8} \mathrm{O}$ uso, portanto, de apenas um ou outro indicador significa que os estudos estatísticos e econométricos apresentam uma série de limitações (Ariyoshi et al., 2000). Em particular, nenhuma medida da intensidade do uso de controles de capital, confiável e, amplamente, aceita, estaria disponível em nível internacional e muitos estudos apenas se restringiriam a utilizar variáveis dummy para a presença ou não de controles. A solução do impasse parece estar na adoção de indicadores distintos que propiciem uma visão mais holística do processo de globalização financeira e a verificação de resultados com base em uma leitura conjunta das abordagens. A consideração conjunta dos indicadores tende a identificar conclusões mais robustas do processo de abertura e integração financeira. É essa a perspectiva adotada no trabalho.

Os indicadores aqui propostos possuem características próprias, o que permite a avaliação de efeitos de fatos distintos sobre a economia, um denotando a legislação propriamente dita e o outro, os fluxos - a utilização de ambos permite

(7) Ele desenvolve uma medida gradativa para a liberalização da conta capital, mensurando sua abertura em uma escala de 0 a 8 , diferentemente, dos estudos anteriores que apenas distinguiam com uma variável binária entre a existência ou não de controles (0 ou 1). Vide Eichengreen e Leblang (2002) para uma discussão sobre as limitações da utilização desses dados.

(8) Vide Kose et al. (2006) para uma discussão mais detalhada entre indicadores de facto e de jure. 
uma visão mais ampla da realidade subjacente e, assim, uma análise mais rica. É importante frisar a independência dos indicadores, cada qual avaliando um aspecto específico do processo de abertura financeira do País. Essa hipótese é confirmada pelo teste de correlação de Spearman. ${ }^{9}$ Diante do exposto, avaliar-se-á a abertura e a integração financeira do País com base em dois indicadores distintos, uma medida de jure e uma de facto. $\mathrm{O}$ indicador de jure (ICC), descrito adiante, segue a tradição inaugurada por Cardoso e Goldfajn (1997), ainda que com algumas adaptações metodológicas, mas mantendo o sentido de apresentar uma alternativa mais detalhada do que os índices construídos com base nos relatórios do FMI. Aqui, cada mudança normativa é avaliada em seu caráter restritivo ou liberalizante e o total das medidas implementadas é que vai definir o sentido da política externa. Por outro lado, os demais indicadores não conseguem esse grau de precisão, pois apenas espelham a existência ou não de controles sobre fluxos de capitais em treze diferentes categorias. Além disso, o ICC permite captar as mudanças em períodos temporais menores do que a periodicidade anual dos relatórios do FMI, permitindo captar as variações da legislação cambial durante os vários episódios de gestão das crises financeiras mundiais. Precisão que os relatórios do FMI não proporcionam ao pesquisador.

Para a abordagem de facto, utiliza-se uma medida quantitativa de abertura financeira com base nos fluxos financeiros reais registrados no período. Segue-se a sugestão de Prasad et al. (2003) para trabalhar com indicadores quantitativos capazes de capturar a abertura financeira de fato, não somente a "de direito" que se refere aos aspectos normativos, como o ICC. O indicador IAF (adiante apresentado), baseado nos fluxos financeiros, não permite uma avaliação sobre os controles de capitais do país, mas proporciona uma caracterização direta dos fluxos financeiros, independentemente, do arcabouço legal editado pelas autoridades monetárias. Ambas as abordagens complementam-se.

\section{Abertura financeira e desempenho macroeconômico no Brasil: algumas evidências empíricas}

O objetivo desta seção é avaliar, empiricamente, as implicações macroeconômicas do processo de abertura financeira do País implementado a partir dos anos 1990, averiguando seus efeitos sobre o crescimento, taxa de juros e taxa de câmbio. Para tanto, utiliza-se um instrumental econométrico para análise de séries temporais, baseado na metodologia dos vetores autorregressivos (VAR). ${ }^{10}$ Com o indicador de mensuração do grau de controle de capitais (ICC), quantificaram-se as mudanças trimestrais ocorridas na legislação que afetam o

(9) A hipótese nula da independência dos indicadores não pode ser rejeitada a um nível de $5 \%$ de significância $(\mathrm{rs}=0,19)$.

(10) Os resultados dessa seção foram obtidos por meio da utilização do software econométrico Eviews 5. 
fluxo de capital por meio das alterações ocorridas no controle de entrada e saída de capitais. Após, de posse do comportamento dessa proxy, verificou-se o resultado da dinâmica de sua interação com as variáveis PIB, taxa de câmbio e juros - dois dos principais preços em uma economia em desenvolvimento afetados pela dinâmica dos fluxos externos. Adotou-se o mesmo procedimento com o índice de abertura financeira (IAF) que relaciona o somatório de ativos e passivos financeiros externos com respeito ao PIB.

\subsection{Impactos da abertura financeira com base no Índice de Controle de Capitais (ICC)}

Para a mensuração da evolução das medidas implementadas sobre o fluxo de capitais, foi utilizada a legislação de capitais estrangeiros e câmbio do País, constante de Soihet (2002), que totaliza um universo de 189 normativos para o período 1990-2000. A partir de 2001, foi realizada a coleta da legislação de capitais estrangeiros e câmbio com base nas normas editadas pelo Banco Central, sobretudo as do Departamento de Capitais Estrangeiros e Câmbio (Decec) e, após, pela Gerência Executiva de Normatização Câmbio e Capitais Estrangeiros (Gence), totalizando 106 normativos até Junho/2006. Assim, reuniram-se 295 normativos nesse período relacionados a entradas e saídas de capitais. ${ }^{11}$ De acordo com a classificação, no universo de 295 normativos, 47,96\% são liberalizantes, $12,24 \%$ são restritivos e 39,80\%, regulamentares. Agrupada e classificada a legislação pertinente a movimento de capitais, partiu-se, propriamente, para construção do índice. O índice é construído com base nos indicadores RI (Restrictions on Inflows) e RO (Restrictions on Outflows), os quais expressam o saldo dos normativos sobre entradas e saídas de capitais respectivamente. O indicador RI refere-se, portanto, às alterações ocorridas no controle à entrada de capital (variando de $-1 \mathrm{a}+1$ ) e RO refere-se às alterações no controle a saídas de capital, variando, analogamente, de -1 a $+1 .^{12}$ Diferentemente, entretanto, da concepção original de Cardoso e Goldfajn (1997), os quais construíram dois índices com base em combinações lineares distintas entre as medidas de restrições sobre inflows e outflows (RI e RO) e, a exemplo de Pires (2004), não se

(11) De acordo com o critério adotado, uma norma considerada liberalizante é aquela que tem a intenção de incentivar a movimentação de capitais como, por exemplo, dar liberdade para remessa de capitais e autorizar a aplicação dos investidores nacionais em títulos emitidos no exterior (DRs). Uma norma restritiva, ao contrário, é aquela que desestimula a entrada e saída de capital estrangeiro. Já, uma legislação de caráter regulamentar é aquela a que tem apenas a intenção de normatizar ou comunicar um fato e por isso tem, em princípio, um efeito neutro sobre os fluxos de capitais. A lista de alterações normativas ocorridas na legislação que afeta o fluxo de capitais entre 2001 e 2006 pode ser disponibilizada via e-mail pelos autores.

(12) Por uma questão de facilidade e conveniência aos exercícios econométricos, optou-se, aqui, por uma leitura do índice para um enfoque do nível de liberalização da conta capital - objeto primário desse estudo. Assim, a uma medida liberalizante foi atribuído um valor +1 e -1 , quando restritiva. O predomínio de medidas liberalizantes passa, então, a ser lido pelo crescimento direto do índice. 
consideraram diferenças qualitativas no efeito dos normativos referentes à entrada ou à saída de capitais, atribuindo pesos similares a todas as normas da legislação. A fórmula utilizada é, portanto, uma combinação linear simples, qual seja:

$$
\mathrm{ICC}=\mathrm{RI}+\mathrm{RO},
$$

em que $R I$ representa restrições à entrada e $R O$, restrições à saída. ${ }^{13}$

Além dessa alteração, capturaram-se os efeitos de cada normativo editado no período com relação ao fluxo de capitais. Por definição, os valores 1 ou -1 não conseguem espelhar o impacto distinto de cada norma legal, requerendo a adoção de valores intermediários nesse espectro, o que foi considerado na avaliação de cada normativo componente do ICC. De fato, algumas normas afetam variados fluxos de capitais enquanto outras são endereçadas, especificamente, a certo fluxo de capital. Além disso, a legislação de capitais no Brasil é caracterizada por uma hierarquia de normas, envolvendo emendas constitucionais, abolindo, por exemplo, as diferenças entre firmas nacionais e estrangeiras para qualquer finalidade econômica (Emenda 06, de 8 ago. 1995). Também, passando por cartascirculares (o instrumento legal que torna pública as decisões da alçada de um diretor do BC, geralmente, confinada a aspectos operacionais de uma decisão do board daquela instituição (exauradas por meio de circulares)), ou seja, leis, decretos, resoluções e normas inferiores que devem ser avaliados de acordo com sua importância e tipo de decisão envolvida, verificando se realmente afetam os fluxos financeiros ou apenas ficam restritos ao plano normativo. Outra desvantagem do ICC original a ser superada refere-se a considerar cada instrumento normativo, independente de ser uma lei, resolução do Conselho Monetário Nacional (CMN), uma decisão da Diretoria do BC (Circular), um decreto presidencial como se contivesse apenas uma simples medida, não distinguindo as normas com relação à sua "profundidade" normativa. Há inúmeros casos para os quais uma única norma traz várias mudanças na regulamentação cambial por meio de diversos dispositivos, algumas vezes, combinando medidas restritivas e liberalizantes no mesmo instrumento legal. Essa concepção do índice afeta, portanto, o "tamanho" do índice e, consequentemente, poderá comprometer sua qualidade e todas as conclusões econométricas daí derivadas.

(13) Entende-se que essa opção consegue espelhar corretamente a evolução normativa implementada. Em uma situação em que o $\mathrm{BC}$ emite uma Circular liberalizante a fluxos de entrada e três outras liberalizantes à saída de capitais, o ICC deverá espelhar esse sentido liberalizante, enquanto for mantida sua concepção original. O ICC (= RI - 0,5 RO) seria igual a -0,5 (sic), indicando acréscimo do controle de capitais e distorcendo a realidade subjacente, ou seja, um sentido restritivo que não consegue indicar a situação do caso concreto de um período em que houve apenas a edição de normativos liberalizantes. Isso distorce, por conseguinte, quaisquer análises econômicas posteriores. Já, o cálculo direto proposto resulta em um valor igual a 4, o que indica, quantitativamente, o caráter qualitativo de liberalização das medidas no período. É com tal fundamento matemático que o ICC é calculado. 
Feitas tais ressalvas, estimou-se o ICC. Basicamente, o índice determina que, em média, o comportamento do BC pode ser descrito como que agindo em direção à liberalização da conta capital no período 1994-2007, tanto com relação a influxos quanto a saídas de capitais. A análise gráfica confirma a hipótese de abertura gradual e crescente da conta capital a partir da década de 1990 no mesmo sentido do apontado por Cardoso e Goldfajn (1997); Soihet (2002); Ferrari et al. (2005); Paula e Silva (2004):

Gráfico 1

ICC acumulado para a economia brasileira (1990-2006)

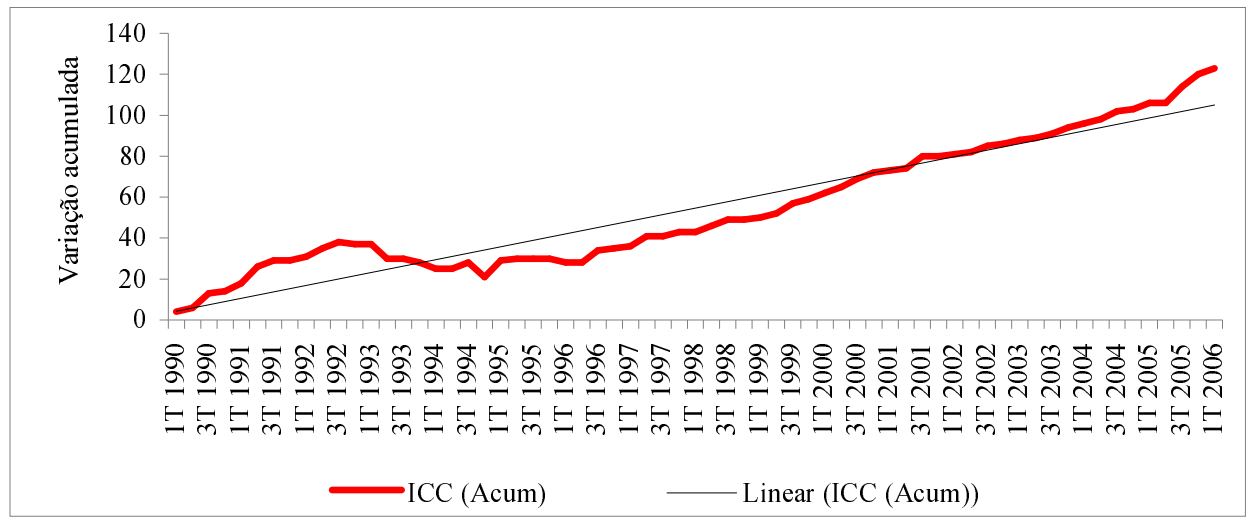

Fonte de dados brutos dos normativos: Soihet (2002)/Banco Central do Brasil. Elaboração própria.

Além do ICC, as demais séries analisadas tiveram como fonte de dados brutos os sítios do Ipeadata e do Banco Central na internet, com as seguintes especificações:

Quadro 1

Especificações dos dados brutos

\begin{tabular}{|l|l|}
\hline Série & Especificação \\
\hline Taxa de juros real & $\begin{array}{l}\text { Taxa selic-over, que teve como fonte o BC, deflacionada pelo IPCA } \\
\text { (TXREALSA) }\end{array}$ \\
\hline Taxa de câmbio & Nominal, série fornecida diretamente pelo BC (LNCANOMSA) \\
\hline PIB & $\begin{array}{l}\text { Preço de mercado. Série encadeada do índice trimestral de base móvel com } \\
\text { ajuste sazonal (média } 1990=100) \text {, fornecido pelo IBGE (LNPIB) }\end{array}$ \\
\hline
\end{tabular}

Fonte: www.ipeadata.gov.br; $\underline{w w w . b c b . g o v . b r}$.

Delimitaram-se como período de abrangência deste estudo os anos que vão de 1994 até 2006, tomando-se, em conta, uma periodicidade trimestral. ${ }^{14}$

(14) Consideram as séries amostrais a partir do terceiro trimestre/1994 até o segundo trimestre/2006, fechando, assim, períodos anuais completos, de forma a minimizar problemas de sazonalidade nos dados porventura existentes. 
Especificamente, a partir da implementação do Plano Real, os indicadores macroeconômicos começaram a apresentar melhores resultados sem a volatilidade do período inflacionário imediatamente anterior, o que poderia dificultar a modelagem e extração de resultados significativos. Procedeu-se, ainda, o ajuste sazonal $^{15}$ e, após, as séries passaram por uma transformação monotônica em logaritmos. ${ }^{16}$ A estacionariedade das séries foi verificada, tomando-se por base a realização dos testes ADF e PP, cujos resultados estão descritos no final do trabalho (Anexo 1). ${ }^{17}$ Não se detectou autocorrelação nos resíduos dos modelos adotados para testar a presença de raiz unitária. Os testes indicam que a variável TXREALSA é estacionária em nível, ou seja, I(0), ao passo que as demais variáveis LNICC, LNPIB e LNCANOMSA ${ }^{18}$ são estacionárias quando se toma a primeira diferença e, nesse caso, são ditas I(1).

Dado que a maioria das séries apresenta uma dinâmica não estacionária, investigou-se, ainda, a presença de cointegração dos dados, por meio de testes bivariados. ${ }^{19}$ Os resultados apontam para a não cointegração das séries ou a inexistência de equilíbrio estável de longo prazo entre as variáveis. Assim, só se pode falar em inter-relação entre as variáveis no curto prazo e todas as conclusões deverão ser tiradas apenas para o curto prazo. Isso implica em que o processo de liberalização financeira no Brasil, capturado tanto pelo ICC quanto pelo IAF, não está associado, no longo prazo, com o comportamento do PIB. As séries podem, então, flutuar arbitrariamente longe entre si. De fato, a série da taxa de juros depreende um processo estacionário de ordem diferente do ICC e IAF, o que per se significa que as séries não podem cointegrar, por definição (Enders, 2004, p. 322). Esse resultado implica em que a capacidade de utilização do processo de liberalização financeira como mecanismo de redução substancial de componente da taxa de juros no País associado à incerteza jurisdicional, a la Arida, não apresente efeitos permanentes no longo prazo, no máximo, sendo verificados no curto prazo. Isso implica, também, em que a abordagem econométrica deverá ser conduzida em um modelo VAR em diferenças de séries, sem adição de um vetor

(15) $\mathrm{O}$ ajuste sazonal empregado nas séries foi àquele pertencente ao pacote estatístico Eviews 5 , método da diferença da média móvel aditiva. A série ICC, baseada nas alterações da legislação pelas autoridades monetárias, não sofreu ajuste sazonal, dada a independência da construção do índice em relação aos meses do ano. A série do PIB já foi utilizada, originalmente, com dados dessazonalizados.

(16) A série de taxa de juros fica expressa diretamente em seus valores percentuais, não requerendo uma transformação logarítmica.

(17) A quantidade de defasagens escolhida para a caracterização de cada série teve, como critério de escolha, a estatística Schwarz (CIS).

(18) Ao implementar a transformação logarítmica, decidiu-se acrescentar o prefixo LN ao nome indicador das variáveis.

(19) Esse procedimento também é necessário para definir a fórmula específica a ser usada no teste de causalidade de Granger (Granger et al., 1998). 
de correção de erro - no caso, o modelo foi melhor especificado com uma defasagem $(\operatorname{VAR}(1)) .^{20}$

Procedeu-se, em seguida, a verificação de possíveis quebras estruturais nas séries sob análise. Dentre as variáveis utilizadas, a série cambial registra um ponto de quebra decorrente da mudança de regime cambial no início de 1999. O teste de Chow, todavia, tanto para a série em nível quanto em diferenças efetivamente incluída na modelagem VAR - não indica significância estatística dessa mudança de regime cambial. ${ }^{21}$

Para a etapa subsequente, buscam-se evidências nas funções impulsoresposta, na análise da decomposição de variância e testes de causalidade de Granger. A finalidade da estimação das funções de impulso-resposta consiste em averiguar de que forma o comportamento das variáveis correspondentes aos PIBs, taxas de juros e de câmbio responde a alterações na quantidade de controles sobre a conta capital, aqui representada pela proxy ICC. As respostas a um impulso no ICC estão representadas no Anexo 2.

Quanto ao Produto, os resultados indicam que maior abertura financeira gera um efeito final predominantemente, ou seja, o resultado favorece a hipótese de que uma ampliação do grau de abertura da conta capital poderá causar efeitos prejudiciais à economia, no caso, persistentes por seis meses. Por outro lado, a liberalização da conta capital implementa um viés predominantemente declinante, sobre o nível da taxa de juros praticada no País. Tem-se, assim, um resultado, em um primeiro momento, contrário, verificando-se que um impulso na direção da abertura financeira tende a reduzir o nível de juros e, ao mesmo tempo, a produzir respostas negativas sobre o nível de atividade econômica. Esse resultado parece apontar para o fato de que o aumento da liberalização tende a reduzir a taxa de crescimento do PIB ao tempo em que também tende a reduzir o nível de juros. Ainda que a abertura financeira reduza a taxa de juros reais no Brasil, esse fato não vem sendo acompanhado pela aceleração da taxa de crescimento do Produto. Isso significa que o efeito positivo da abertura financeira sobre a taxa de juros não consegue surtir efeitos sobre o ritmo de atividade econômica - algum link tende a ser fraco. Dado que o link entre juros e PIB é significativo, relação identificada nos termos do teste de Granger, sugere-se que a relação direta entre abertura financeira e juros parece não ser robusta. Realmente, os testes complementares de Granger e da decomposição da variância corroboram essa hipótese.

Uma interpretação adicional sugere que o nível de juros reais possa ser tão alto que o efeito do processo de liberalização financeira seja insignificante e não

(20) Foi utilizado o critério de Schwartz para a seleção do número de defasagens.

(21) Uma quebra no nível da série, como parece ser o caso do câmbio, em uma série diferenciada passa a ser uma simples irregularidade sem relevância estatística. Esse resultado avaliza a conclusão dos testes de raiz unitária bem como a não inclusão de variável dummy na construção da modelagem econométrica. 
esteja conseguindo implementar um viés expressivo para sua redução que chegue, realmente, a alavancar o crescimento. Por outro lado, essa hipótese perde força quando se verifica que o teste de Granger indica não ser esse resultado da relação entre abertura financeira e redução de juros per se significativo, o que traduz, formalmente, sua fraca capacidade de reduzir juros e, por esse canal, induzir o crescimento. Tal resultado vai de encontro à hipótese de que uma maior abertura financeira tende a reduzir a taxa de juros de forma tão expressiva que propicie a verificação de resultados positivos sobre o nível de atividade econômica. Isso equivale a dizer que a redução do componente de risco relativo à 'incerteza jurisdicional' no Brasil não é capaz de reduzir, de forma significativa, o nível de juros reais praticados no país, constituindo uma relação fraca como já fora apontado por Gonçalves et al. (2007). ${ }^{22}$ Resta, assim, o canal direto entre abertura financeira e PIB, que não chega a ser virtuoso nem a constituir uma ligação significativa - de fato, para um período marcado por uma ampla abertura financeira associada a um nível de atividade econômica, predominantemente, fraco, o resultado é bastante plausível. Já, os resultados da relação do ICC com o câmbio sugerem uma tendência de depreciação da moeda local, da mesma forma, também não significativa. De qualquer modo, o fato parece estar atrelado mais fortemente à administração da banda cambial que foi sendo corrigida com base na inflação doméstica, seguida de uma desvalorização mais acentuada a partir de 1999, dado o novo regime de câmbio flutuante, culminando com a saída de capitais mais acentuadas em $2002 .^{23}$

O teste de causalidade de Granger foi implementado para examinar se os valores defasados de uma determinada variável $y$ precedem uma outra variável $x$, o que permite inferir sobre o sentido da causalidade entre as variáveis. ${ }^{24} \mathrm{Com}$ um

(22) Gonçalves et al. (2007) testam a hipótese de Arida de que riscos associados à inconversibilidade da moeda nacional constituiriam um determinante expressivo do nível da taxa de juros básica praticada no Brasil. Utilizando dados de painel para uma ampla amostra de países, seus resultados são "bastante desfavoráveis" a essa hipótese.

(23) A taxa cambial foi o mecanismo de equacionamento das contas externas a partir de 1999, refletindo a saída de capitais do país dadas as incertezas do cenário política nacional à época. Esse mesmo caráter financeiro e volátil dos fluxos de capitais passou, inclusive, a ser característico dos fluxos decorrentes das exportações brasileiras, como fora apontado por Sicsú (2007). Apesar da flexibilização proporcionada pela MP315 (agosto/2006), possibilitando a manutenção de 30\% da cobertura cambial, além da ampliação do prazo de internação das divisas provenientes das exportações, o $\mathrm{BC}$ verificou, posteriormente, à edição dessas medidas a manutenção do influxo e do período médio de internação de $100 \%$ das receitas das exportações brasileiras, o que indica que os recursos captados pelos exportadores estão sendo mantidos na esfera do sistema financeiro doméstico.

(24) Preliminarmente à aplicação do teste propriamente dito, diante de séries temporais não estacionárias, examinou-se se as variáveis sob análise cointegram ou não, duas a duas, conforme Granger et al. (1998). Basicamente, isso define a formulação específica do teste: se há cointegração entre as variáveis, adicionase um termo de correção de erro ao modelo convencional do teste utilizado para o caso da inexistência de cointegração. No presente caso, os resultados apontam pela não cointegração das séries, possibilitando a aplicação do teste de Granger convencional (Anexos 3 e 4). 
nível de significância de $5 \%$, depreende-se que as variações no PIB precedem no sentido de Granger o ICC, ou seja, ajudam a explicar o ICC. Ao se verificar que o sinal do PIB, na equação restrita do ICC, é positivo, isso aponta para a hipótese de que o processo de abertura financeira foi implementado conforme a conjuntura econômica: somente em períodos em que a conjuntura externa e as contas do balanço de pagamentos permitiam, é que a autoridade monetária prescindia do uso de controles, reforçando o caráter endógeno dos controles de capitais no Brasil, como foi identificado por Cardoso e Goldfajn (1997). ${ }^{25}$ A abertura financeira de caráter mais estrutural teve sequencia gradual, dadas as limitações das crises financeiras externas que caracterizaram o período recente e ensejaram medidas de controle sobre os fluxos de capitais. Significa, dado esse resultado robusto, que um acréscimo no PIB, ex ante, tende a produzir ou a permitir o aumento da abertura sob a expectativa de alavancagem do nível de atividade, resultado, todavia, não confirmado. Ainda que não chegue a, efetivamente, constituir uma alavanca mais expressiva no sentido do crescimento, a relação inversa de precedência do ICC sobre o PIB não é significativa, não sustentando a hipótese da influência da abertura da conta capital como um fator determinante para a aceleração do crescimento do Produto.

O exercício econométrico, portanto, indica mais fortemente que o grau de abertura financeira do País está muito atrelado ao nível de atividade econômica, o que corrobora a hipótese de que o grau de controle de capitais no período sofreu forte influência das condições econômicas locais, no mesmo sentido da hipótese de endogenia dos controles (Cardoso; Goldfajn, 1997). Em momentos de crise, quando o país se defrontou com condições financeiras adversas, afetando o nível de atividade econômica, em uma conjuntura de falta de liquidez internacional, o nível de controles foi relaxado pela autoridade monetária na tentativa de contornar o quadro econômico adverso. O resultado esperado dessa política, de resposta do PIB em relação à variação do ICC, entretanto, não foi expressivo. Acabou frustrando as expectativas de utilizar a abertura financeira como um instrumento gerador de benefícios macroeconômicos significativos, em contraposição ao pressuposto implícito por Arida de efeitos exógenos da abertura financeira sobre a atividade econômica. Além disso, os efeitos de uma variação no ICC não são claros no sentido de aumento da atividade econômica doméstica, como o teste de impulso-resposta mostrou.

Um segundo resultado, estatisticamente, significativo está associado com a relação entre taxa de juros e PIB: as variações na taxa de juros precedem as

(25) Como enfatiza Rodrik (1998), há um problema de causalidade reversa, geralmente, não enfatizado, envolvido entre liberalização financeira e nível de crescimento, dado que os países costumam remover controles de capitais quando o cenário econômico é favorável. Ainda que exista uma correlação positiva, a liberalização pode ser consequencia e não causa de crescimento.

Economia e Sociedade, Campinas, v. 20, n. 1 (41), p. 79-112, abr. 2011. 
variações no PIB, denotando a relação forte entre as variáveis, como era de se esperar. Esse resultado reforça o resultado prévio de que os fluxos de capitais internacionais não estão garantindo uma trajetória positiva à economia brasileira. De fato, a hipótese de que níveis elevados de taxa de juros estão afetando, negativamente, o nível de atividade doméstica, enquanto atraem e mantêm estoques de capitais, parece plausível com os resultados estatísticos. Já, as demais relações testadas não apresentaram grau de significância estatística apropriado, não permitindo conclusões mais robustas. Especificamente com relação aos efeitos do ICC no sistema - foco deste trabalho -, os testes não permitem maiores conclusões: nenhum resultado é estatisticamente significativo, o que corrobora a hipótese de que o ICC possui pouca influência sobre as variáveis macroeconômicas consideradas. Na verdade, os testes indicam fortemente que o ICC possui um caráter muito mais endógeno no sistema sofrendo os efeitos decorrentes das variações nas demais séries. Isso, inclusive, se dá de forma significativa em relação à atividade econômica como previamente apontado. Ao mesmo tempo, corrobora a hipótese de que o ICC possui pouco poder explicativo sobre o comportamento dessas variáveis. Assim, os resultados obtidos pela função impulso-resposta devem ser avaliados de forma restrita.

Finalmente, a análise de decomposição de variância ${ }^{26}$ (Anexo 5) informa a proporção dos movimentos de uma variável que é devida a seus próprios choques e aos choques das outras variáveis do VAR, relatando a importância relativa de cada inovação para as variáveis componentes do sistema. Essa análise revela que as alterações no PIB (LNPIB) dependem mais das mudanças no próprio comportamento passado do PIB do que em outras variáveis. Identifica-se, também, o baixo poder explicativo do ICC sobre o comportamento do PIB, alcançando um percentual muito pequeno (menor que $2 \%$ ). Por outro lado, o comportamento dos juros teve uma boa influência sobre o resultado do PIB, como era de se esperar, com um importante poder de explicação de seu comportamento de quase $15 \%$ - o resultado parece capturar o efeito da política monetária restritiva sobre o nível de atividade econômica. O ICC, também, é pouco significativo para explicar o comportamento dos juros. Seus choques contribuem, individualmente, com um percentual menor que $1 \%$, praticamente, independente dos resultados dos juros. ${ }^{27}$ Da mesma forma, o ICC surge, aqui, como uma variável bem pouco significativa para explicar o nível da taxa cambial, respondendo, minimamente, por seus erros previstos, contribuindo, de modo individual, com pouco mais de $2 \%$ das

(26) A ordem das variáveis consideradas para a realização dessa análise foi definida a partir dos resultados do teste de Granger.

(27) Assim como o PIB, o comportamento passado dos juros explica a maior parte de suas variações $(93 \%)$. 
variações. ${ }^{28}$ Aqueles efeitos de variações, portanto, no nível de controle de capitais ou seu inverso, no grau de liberalização da conta capital sobre as variáveis pesquisadas, indicados pelos gráficos de impulso-resposta, devem ser considerados, latu sensu, limitados, reforçando as conclusões do teste de Granger.

Assim, o exame conjunto dos resultados supramencionados permite as seguintes inferências dos efeitos do grau de abertura financeira no País para o período em análise. Quanto ao PIB, em que pese a resposta predominantemente negativa, decorrente de um impulso no ICC, mas considerando, de outra parte, sua pequena relevância para explicar o comportamento do Produto junto ao fato de sua precedência não ser significativa, não se pode sustentar um efeito robusto nessa relação. Em outras palavras, os exercícios não identificam uma relação robusta de causação entre grau de abertura financeira e crescimento, portanto os efeitos da abertura financeira sobre o nível de atividade econômica podem ser tratados como limitados. Tal resultado é semelhante ao obtido por Rodrik (1998). Ele concluiu que controles de capitais são essencialmente não correlacionados com desempenho econômico. ${ }^{29}$

Cabe salientar, mais do que mostra a literatura, que a relação entre os efeitos da liberalização financeira e o crescimento econômico, frequentemente, não tem sido conclusiva, pois o presente exercício aponta uma correlação significativa entre as variáveis no sentido inverso. Isso significa que $o$ comportamento do nível de atividade causa, no sentido de Granger, variações no ICC. Pode-se inferir que as autoridades acabam utilizando o nível de controle sobre capitais como um instrumento no sentido de afrouxar ou ampliar os fluxos de capitais do País com o exterior, conforme a conjuntura econômica interna. Assim, o nível de abertura financeira da economia parece ter um caráter muito mais endógeno no sistema do que, propriamente, representar uma variável mais autônoma com efeitos sobre o comportamento das demais variáveis - a hipótese de Arida justamente se sustenta no efeito benéfico da abertura financeira sobre o comportamento da taxa de juros, o que é limitado de acordo com a experiência brasileira recente. Assim, há uma fraca ligação entre abertura e seu efeito sobre o PIB: seja direta ou indiretamente por meio de seu efeito sobre a taxa de juros,

(28) Choques passados na taxa cambial também explicam, em grande parte, suas variações esperadas (mais de $73 \%$ ao longo do tempo)

(29) O estudo de Rodrik (1998) é um dos mais abrangentes e citados na literatura acerca dos efeitos macroeconômicos da liberalização da conta capital. Seu modelo cross section baseia-se em uma proxy para abertura financeira construída a partir dos dados do relatório AREAER do FMI, constituindo o indicador predominante dentre os trabalhos empíricos. Por meio de uma amostra com, aproximadamente, 100 países, desenvolvidos e em desenvolvimento, ele não encontra efeito significativo da variável liberalização da conta capital com relação à renda real per capita entre 1975 a 1989 nem com relação ao nível de investimento ou de inflação. Nesse sentido, não haveria evidências significativas de que países com menos restrições a fluxos de capitais crescessem mais rapidamente ou invertessem mais recursos em suas economias do que países com um nível mais elevado de restrições na conta capital.

Economia e Sociedade, Campinas, v. 20, n. 1 (41), p. 79-112, abr. 2011. 
todavia não significativa, o que não chega a produzir efeitos positivos sobre o PIB. O juro parece estar definindo mais fortemente o nível do PIB, enquanto o ICC não tem "força" suficiente para afetar os juros e o PIB, diretamente ou por meio do canal de uma redução mais forte sobre o nível de juros praticados na economia brasileira.

Em um ambiente de pouca liquidez e insuficiência de recursos para financiar a atividade interna, implementam-se medidas no sentido de facilitar o fluxo de capitais, corroborando a hipótese da endogenia dos controles de Cardoso e Goldfajn (1997), com a finalidade de incentivar o nível de atividade econômica. Apesar desse movimento de abertura da conta capital, não se pôde, entretanto, inferir que a maior conversibilidade do Real tenha gerado efeitos positivos sobre o nível de crescimento econômico, dada essa relação não ser significativa nos termos do mesmo teste de Granger. Os resultados permitem descartar uma relação positiva entre liberalização da conta capital e crescimento, indicando que uma proposta de plena conversibilidade no País não possui embasamento empírico. Esse resultado é muito plausível se avaliarmos que o grau de liberalização da conta capital no período registrou uma ampliação constante e significativa, considerada até completa por Freitas e Prates (2001), enquanto o nível de crescimento econômico manteve-se em patamares restritos, não espelhando, portanto, esse aumento da conversibilidade. Vale dizer que a própria experiência brasileira com o processo de abertura financeira, implementado no sentido de propulsionar a taxa de crescimento do produto interno, não sustenta o alcance de efeitos benéficos de uma decisão política nessa direção. No limite, até se pode inferir pelo sentido contrário, dada a relação inversa encontrada entre as variáveis no exercício econométrico, mas que apontam, ao menos, que os efeitos não são claros. A conclusão parece ser no sentido de que o processo de abertura não é política suficiente ou necessária para acelerar o crescimento.

Com relação aos juros, também, não se pode sustentar uma relação significante entre o grau de abertura financeira e o nível de juros interno praticado no período. Os resultados indicam que um choque liberalizante no ICC tende a implementar um viés reducionista sobre a taxa de juros, entretanto não robusto. Dado o poder explicativo limitado do ICC sobre o comportamento dos juros e o fato de que suas variações não precedem as variações nos juros significativamente, torna-se difícil sustentar uma relação mais forte entre as variáveis como um instrumento de política econômica com essa finalidade, isto é, não se sustenta uma proposta de plena conversibilidade da conta capital como geradora de benefícios nesse sentido. Outrossim, a baixa correlação encontrada entre abertura da conta capital e taxa de juros vai ao encontro do observado por Oreiro et al. (2004). Eles indicaram que, ao longo da década de 1990, o Brasil procedeu na direção de uma conversibilidade crescente da conta de capitais (mudança no nível do ICC), sem 
que houvesse uma tendência de redução mais expressiva no nível de taxa de juros doméstica. A hipótese, então, de que o grau de conversibilidade da conta capital contribui como fator explicativo relevante para o nível de taxa de juros praticado no País não é sustentada pelos exercícios, dada a independência entre as variáveis. Já, com relação aos efeitos da abertura financeira sobre o câmbio, a análise conjunta dos testes não permite sustentar uma correlação mais forte entre o nível de controles de capitais e taxa cambial. De fato, o resultado de que o ICC não gera efeitos significativos no sistema econômico parece ser a conclusão mais forte. Assim sendo, a influência do comportamento da conta capital foi muito restrita, devido a seu caráter ativo limitado bem mais passivo no sistema econômico, no sentido de absorver as variações do comportamento das demais variáveis do que, propriamente, representar um mecanismo político (exógeno) que implemente um maior dinamismo à economia brasileira.

\subsection{Impactos da abertura financeira com base no Índice de Abertura Financeira (IAF)}

Constitui-se uma segunda medida, o IAF, por meio da soma dos fluxos financeiros de entradas e saídas sobre o PIB (em módulo), em uma analogia ao indicador de abertura comercial (exportações mais importações sobre o PIB). Assim,

$$
\mathrm{IAF}=\frac{\sum \text { fluxos financeiros }}{\text { PIB }}
$$

As contas utilizadas são provenientes do Balanço de Pagamentos do País, disponível no sítio do $\mathrm{BC}$ na internet (Anexo 6). Os resultados encontram-se plotados a seguir:

Gráfico 2

Índice de abertura financeira (1994T3 a 2006 T2)

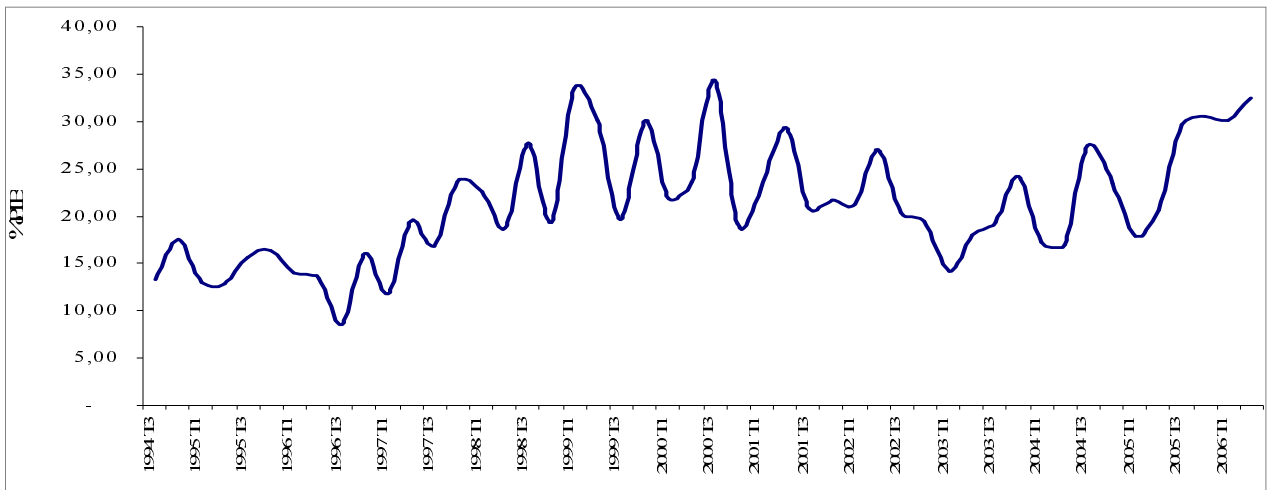

Fonte: Banco Central do Brasil. Elaboração própria 
Pode-se depreender que, com relação ao fluxo real de capitais, no período há uma tendência crescente de integração financeira do País com o exterior, passando de uma média de fluxos de 2,34\% do PIB em 1990/91, a um patamar acima de $32 \%$ do PIB em 2006, além do forte pico de entrada de capitais registrado em 1994. Repetiu-se o mesmo tratamento de dados e análise econométrica feitos anteriormente. ${ }^{30}$ Para selecionar o melhor modelo VAR outra vez, toma-se, como indicativo, o Critério de Informação de Schwarz (CIS) nos moldes já expostos na subseção anterior. O modelo VAR mais apropriado é aquele com uma defasagem (VAR(1)). Definido o número de defasagens, parte-se para a avaliação da estabilidade do VAR estimado, determinando a adequação da estrutura de defasagens. Na sequencia, procedeu-se à análise da função impulsoresposta, cujos resultados são apresentados no Anexo 7.

Com relação ao IAF, um choque positivo nos fluxos tende a gerar efeitos oscilatórios (declinantes) nos períodos seguintes, não se sustentando uma tendência mais acentuada em nenhuma direção. Isso sugere o caráter autônomo e volátil dos fluxos financeiros no tempo, os quais se deslocariam em função de oportunidades de lucro e ganhos de arbitragem em curto prazo, reforçando a hipótese da instabilidade dos mercados financeiros. Quanto ao Produto, os resultados indicam que uma integração financeira mais ampla está gerando um efeito final predominantemente negativo, ou seja, o resultado favorece a hipótese de que uma ampliação do grau de integração financeira poderá gerar efeitos prejudiciais a uma economia emergente, no caso, persistentes por quase um ano. Um resultado expressivo refere-se ao comportamento da taxa de juros em resposta ao choque no IAF. O aumento da integração financeira implementa um viés oscilatório sobre o nível da taxa de juros praticada no País, com uma tendência final de sua majoração - ao contrário do resultado identificado no exercício prévio. De fato, as diferenças nos padrões de comportamento de cada série utilizada como proxy nos exercícios (ICC e IAF), possivelmente estarão correlacionando-se, de modo diferente, com as demais séries testadas. De qualquer forma, esse comportamento aponta para a hipótese de que a integração de um país em desenvolvimento aos fluxos de capitais internacionais, sem a utilização de controles de capitais adequados, pode defrontar-se com um viés altista sobre as taxas de juros para a atração e manutenção de capitais. Já, os resultados da relação do IAF com o câmbio sugerem efeitos oscilatórios na taxa de câmbio. Ao mesmo tempo, há uma tendência mais pronunciada em direção à depreciação da moeda doméstica, mesmo resultado do exercício anterior. Com isso, permite-se interpretar o resultado como uma associação com as saídas de capitais do País, em regime de taxa flutuante, especialmente, após o ano 2000, quando a liberalização

(30) Por uma questão de simplificação, alguns testes serão apenas comentados. O detalhamento pode ser disponibilizado aos interessados. 
sobre outward transactions passa a ser mais pronunciada. ${ }^{31}$ Nesses termos, mesmo sendo reduzida a magnitude dos efeitos indicados sobre a taxa cambial, é plausível assumir que uma integração financeira mais ampla acrescente um elemento de volatilidade adicional a esse mercado, ainda que limitado, mas sem uma tendência definida ex ante em uma ou outra direção. Isso é condizente com a hipótese de que um aumento na liberalização da conta de capitais ou sobre os fluxos de capitais subjacentes, poderá causar um desajuste no mercado de câmbio, em oposição ao proposto por Arida (2003a).

Em contrapartida, os testes de causalidade de Granger (Anexo 8) apontam apenas dois resultados significativos. Basicamente, com um nível de significância de $5 \%$, pode-se afirmar que as variações no IAF não precedem as variações no PIB. De fato, parece que a maior integração financeira não está explicando o comportamento do PIB: enquanto se registrou uma tendência de aprofundamento da integração financeira do Brasil com os fluxos financeiros internacionais, o ritmo de crescimento da economia brasileira manteve-se reduzido em relação à média mundial. Nesses termos, o resultado de que a abertura financeira não explica o atual padrão de crescimento econômico do Brasil corrobora a hipótese de que a influência dos fluxos de capitais internacionais no País, em termos de crescimento econômico, foi, no máximo, limitada durante o período, adicionando pouco poder explicatório à evolução do PIB. Assim, é plausível considerar que a inserção internacional do Brasil não está produzindo uma trajetória virtuosa à economia local, ao contrário do esperado por Arida (2003). Um segundo resultado é que a taxa de juros causa, no sentido de Granger, o PIB, também identificado no exercício anterior. Essa relação desvela o efeito da política monetária restritiva característica do período, baseada em níveis altos de taxas de juros para controlar o nível de preços (em termos internacionais), mecanismo, também, utilizado para atrair influxos de capitais internacionais, associado a controles de capitais decrescentes no período. Isso ajuda a explicar o nível de atividade da economia doméstica, especialmente, após 2003, quando a economia global passou a andar em ritmo mais rápido e o Brasil continuou em nível aquém (IMF, 2006). ${ }^{32}$ As demais relações testadas não são, estatisticamente, significativas. De qualquer maneira, com relação aos efeitos do IAF sobre taxa cambial e de juros no sistema, é provável que o IAF preceda juros e câmbio, o que significa que uma abertura aos fluxos de capitais internacionais poderá afetar ambos os preços domésticos. Nenhum dos resultados, entretanto, é estatisticamente significativo, o que reforça a

(31) Naturalmente, tal hipótese necessita de pesquisa adicional, que ultrapassa o objetivo deste trabalho.

(32) A previsão de crescimento do FMI (WEO, Apr. 2008, p. 2) para 2009, também, não é animadora. Enquanto o órgão espera uma média de crescimento de $6,6 \%$ para as economias emergentes, em desenvolvimento e, mais especificamente, dentre o BRIC, $8 \%$ para Índia, 9,5\% na China e 6,3\% na Rússia, a expectativa é de 3,7\% para o Brasil. 
hipótese de que o IAF possui poder explicativo limitado sobre o comportamento dessas séries, mesma conclusão apontada na seção anterior.

O procedimento de decomposição de variância (Anexo 9) desvela que as alterações no PIB (LNPIB) dependem mais das mudanças no próprio comportamento passado do PIB do que das mudanças em outras variáveis, mesmo resultado obtido na análise com o ICC. Novamente, o comportamento da taxa de juros é relevante para explicar o PIB, influindo em torno de $15 \%$ de seus resultados, similar ao encontrado no exercício anterior. Por sua vez, o IAF não é relevante para explicar o comportamento do PIB e juros: seus choques contribuem em torno de $1 \%$ do comportamento dos juros e menos do que isso para o PIB. Com relação ao câmbio, a evolução dos fluxos de capitais no período, representada pelo IAF, também não é relevante para explicar suas variações, alcançando, novamente, menos que $1 \%$ de poder explicativo. Efeitos decorrentes de um nível mais alto de integração financeira do País com o exterior devem, portanto, ser considerados limitados com respeito ao nível de crescimento da economia doméstica e à volatilidade sobre a taxa de juros e de câmbio.

Buscou-se, assim, analisar os efeitos das variações no nível de integração financeira do País com o exterior sobre aquelas variáveis. Os resultados do exercício reafirmam outro geral obtido com o ICC, qual seja, da fraca possibilidade de utilizar-se da gestão externa da economia como mecanismo gerador de um maior crescimento interno. Esse resultado alinha-se com a constatação de Minella e Goldfajn (2005) de que o processo de abertura financeira não significou o alcance de maiores benefícios em termos de ritmo de crescimento econômico. Da mesma forma, a taxa de juros parece ser afetada positivamente. Quanto ao Produto, os resultados, em conjunto, sugerem que não se criou, no período, uma relação positiva entre o aumento no nível de integração financeira do País com o exterior e o crescimento econômico. A tese de que uma maior integração financeira com o exterior geraria amplos benefícios econômicos para um país em desenvolvimento não encontra suporte na experiência recente do Brasil, na economia globalizada. Ao contrário, apesar de limitada, os testes apontam uma pequena tendência na direção contrária: um choque positivo sobre o grau de integração financeira tende a gerar efeitos prejudiciais sobre o crescimento da economia - na verdade, dado que as séries acabam tendo correlação praticamente nula, não se permitem maiores conclusões a respeito, mas se descarta, desde já, uma relação virtuosa. Além disso, como notam Bastos, Biancareli e Deos (2006), economias emergentes que evitaram programas extremos de liberalização da conta capital apresentaram melhor desempenho associado a um risco mais controlado em suas estratégias de integração externa.

O resultado corrobora a suposição de que o nível de integração financeira da economia brasileira no período não foi, na melhor das hipóteses, um fator 
determinante para o resultado final do PIB - caso fosse relevante, poderia atuar em prejuízo do crescimento. A hipótese de que uma maior integração financeira não gera efeitos conclusivos sobre as economias periféricas está de acordo com as evidências expostas na literatura recente (World Bank, 2005). A observação de Prasad et al. (2003, p. 6) é clara, afirmando que "[...] é difícil estabelecer uma relação causal robusta entre integração financeira e desempenho do crescimento do produto". ${ }^{33}$ O resultado pode, também, ser explicado com a ajuda de Eichengreen e Leblang (2002). Segundo os autores, em períodos com o registro de sucessivas crises financeiras, inclusive de escala global como o estudado, um maior grau de integração financeira poderia acabar impactando, negativamente, o crescimento dos países de forma mais acentuada do que os efeitos positivos decorrentes de uma suposta melhor alocação de recursos e eficiência econômica que a integração aos fluxos globais pudesse proporcionar. Estando esses efeitos em direções opostas, o efeito líquido de um aumento da integração financeira acabaria sendo específico a cada contexto. No presente caso, o efeito líquido seria negativo, ainda que limitado, não suportando per se uma proposta de adoção de um regime de plena conversibilidade da conta capital. Com relação ao nível de juros, os testes, também, não permitem conclusões mais robustas, dado não ser significativa a relação entre IAF e juros. De qualquer forma, é possível afirmar que, se existem efeitos da maior integração financeira sobre juros, estes podem ocorrer por meio da presença de um viés oscilatório e altista sobre o nível das taxas praticadas no País. Isso aponta para a hipótese de que a integração de um país em desenvolvimento aos fluxos de capitais internacionais leva à necessidade da prática de taxas de juros mais altas para sua atração e manutenção. Já, os resultados da relação do IAF com o câmbio sugerem efeitos oscilatórios sobre a taxa de câmbio, mas sem a definição de uma tendência ex ante em direção a uma ou outra direção. De qualquer forma, a maior integração financeira pode atuar no sentido da desestabilização do mercado cambial, com efeitos deletérios sobre a economia real, o que, inclusive, pode acabar afetando o volume de fluxos financeiros. Isso confirma a hipótese de que um aumento da integração financeira causaria um desajuste no mercado cambial até como decorrência da volatilidade e características intrínsecas dos capitais. A conclusão paralela reforçada nos dois modelos VAR estimados é de que taxa de juros possui influência significante

(33) Sua survey não encontra evidências definitivas de que a abertura e integração financeira tenham aumentado o crescimento nos países em desenvolvimento; ao contrário, sugerem que poderiam estar associadas à maior volatilidade da função consumo nessas economias, dado o acesso pró-cíclico aos mercados de capitais internacionais. Ao mesmo tempo, a regressão entre a mudança no nível de abertura da conta capital (captada pela soma dos fluxos de entrada e saída de capitais em relação ao Produto) e a taxa de crescimento per capita do Produto, para uma amostra de países em desenvolvimento entre 1982 e 1997, aponta, essencialmente, nenhuma associação entre as variáveis (p. 26), mesmo depois de controlar efeitos como escolaridade e renda inicial, taxa média de investimento, instabilidade política e localização regional. A conclusão mais forte é de que abertura financeira não constitui uma condição necessária para alcançar uma taxa de crescimento alta. 
sobre o PIB. Isso desvela a forte relação (inversa) entre o nível de atividade econômica e a taxa de juros interna do País, com prejuízo para o bem-estar da sociedade brasileira.

\section{Considerações finais}

Até a primeira metade dos anos 1990, o otimismo inicial com a globalização financeira parecia encontrar respaldo na realidade. A forte retomada na entrada autônoma de capitais privados em regiões periféricas permitiu a aceleração no crescimento econômico e deu sustentação aos programas de estabilização monetária baseados na âncora cambial, em especial, na América Latina. A partir da crise mexicana de 1994, principalmente, da crise asiática de 1997-1998, o otimismo liberalizante deu lugar a um crescente pessimismo. Em paralelo, verificou-se, até meados de 2002, uma nova retração na entrada líquida de capitais privados em magnitude equivalente à verificada na crise da dívida dos anos 1980. Recorrência de crises financeiras, ampliação no fosso de desenvolvimento entre ricos e pobres, assimetrias no comércio internacional e percepção de que a instabilidade parecia ser regra - e não, exceção como sugeria parcela importante do establishment, lançaram uma sombra de crescente insatisfação quanto aos resultados da globalização. No plano acadêmico, as evidências empíricas sugeriam que as ligações entre liberalização financeira e crescimento não eram robustas, ao contrário, a instabilidade macroeconômica parecia ser o aspecto dominante na experiência de abertura financeira entre os países em desenvolvimento (Rodrik, 1998; Edison et al., 2002 ${ }^{34}$; Prasad et al., 2003; World Bank, 2005 ${ }^{35}$ ).

O Brasil não foi uma exceção nesse quadro mais geral. Sua experiência parece reafirmar que as ligações entre liberalização financeira e crescimento econômico são, no mínimo, questionáveis. Como sugeriu Bhagwati (1998), não se

(34) Edison et al. (2002), ao avaliarem a experiência de abertura dentre diversos países, reportam que, enquanto a maioria dos países da OECD (18 de 21) aumentou seu grau de liberalização entre 1973 e 1988, os países em desenvolvimento praticamente se dividiram entre os que aumentaram (15 países), reduziram (12) ou mantiveram inalterado (15) o nível de controles. Aqueles que, em 1973, tinham um grau relativamente alto de liberalização moveram-se à direção da redução da exposição externa. Além disso, nos países em desenvolvimento, após um período de liberalização nos anos 1970, a tendência foi revertida nos anos 1980, recomeçando nos anos $1990 \mathrm{em}$ ritmo, relativamente, mais lento. Assim, apesar de os países industrializados liberalizarem amplamente a conta capital e os países em desenvolvimento caminharem em direção a uma liberalização mais extensa, a maioria dos países em desenvolvimento permanece fazendo uso de instrumentos de controle sobre fluxos de capitais.

(35) O Banco Mundial (2005) aponta que os benefícios esperados em decorrência do processo de liberalização financeira dos anos 1990 ainda não tinham sido verificados diante da recorrência mais forte de crises financeiras internacionais associadas à limitada contribuição da abertura financeira ao crescimento e acesso a financiamento externo das economias em desenvolvimento. 
pode assumir aquela ligação como sendo virtuosa a priori. ${ }^{36}$ Ainda assim, tem-se verificado no País um processo contínuo de transformação na legislação que trata do mercado cambial e da regulação dos fluxos de capital em um sentido claramente liberalizante. Recentemente, Arida (2003a, 2003b, 2004) e Arida, Bacha e Lara-Resende (2003) reacenderam o debate em torno do grau desejável de abertura da conta capital ou de conversibilidade da moeda nacional. ${ }^{37}$ Segundo eles, a possibilidade do Banco Central restringir a livre mobilidade de capitais - se assim o desejar, por quaisquer razões - geraria uma "incerteza jurisdicional" entre a qual criaria um prêmio de risco embutido nas taxas de juros cobradas para a retenção em carteira de ativos denominados em Reais. Tal incerteza só poderia ser eliminada caso o Real se transformasse em uma moeda plenamente conversível e as Autoridades Monetárias (Conselho Monetário Nacional e Banco Central) não pudessem mais, por via infralegal (edição de normativos sob sua competência), atuar sobre aquela conversibilidade. Assim, na opinião daqueles autores, o Brasil poderia avançar na consolidação do atual regime macroeconômico caracterizado pelo tripé câmbio flutuante, superávits fiscais e metas de inflação. Eliminada aquela fonte de "incerteza jurisdicional", abrir-se-ia espaço para uma queda sensível da taxa de juros e a retomada do crescimento econômico em um ritmo superior e de forma sustentável.

A tese da plena conversibilidade de Arida vem sendo criticada em seus fundamentos. No plano teórico, um argumento muito utilizado, originalmente sugerido por Belluzzo e Carneiro (2004), mas também presente em Ferrari et al. (2005); Oreiro, Paula e Silva (2004), é o de que a transformação do Real em uma moeda plenamente conversível do ponto de vista legal não, necessariamente, a tornaria um ativo universal aceito como reserva de valor. Parte-se de uma perspectiva analítica de inspiração keynesiana para se mostrar que a moeda possui um conjunto de atributos específicos que transcendem à função de mera facilitadora das trocas e denominadora comum dos contratos. Na presença de incerteza, os agentes econômicos podem desejar reter ativos líquidos que possam garantir acesso a outras formas de riqueza. Há, portanto, uma demanda por moeda

(36) Bhagwati (1998) registra exemplos ilustrativos de que os ganhos da livre mobilidade de capitais podem ser negligentes. China e Japão, por exemplo, com políticas e experiências históricas distintas, registraram crescimento notável sem conversibilidade da conta capital. O próprio retorno dos países do leste europeu à prosperidade teria sido também alcançado sem a conversibilidade da conta capital. Nesse sentido, perde força o argumento de que a única política sensata, em termos de gestão de fluxos de capitais, seria a busca da desregulamentação total dos fluxos de capitais no lugar da manutenção de controles precaucionais

(37) Aqui, optou-se por tratar, como equivalentes, os conceitos de conversibilidade plena da moeda nacional e liberalização da conta capital e financeira (ou só conta capital, para simplificar). No limite, trata-se de reduzir/eliminar entraves legais para que os detentores de riqueza possam assumir posições ativas e passivas nos mercados doméstico e internacional, a partir da utilização de instrumentos denominados em distintas moedas. Uma diferença relevante acontece entre liberalização financeira e integração financeira. Um país pode ter uma legislação liberalizante e não atrair capitais, como é o caso de muitos países africanos. Por outro lado, pode adotar medidas restritivas e ser um player ativo nas finanças globais, como China e Índia. Ver Prasad et al. (2003).

Economia e Sociedade, Campinas, v. 20, n. 1 (41), p. 79-112, abr. 2011. 
que não está relacionada diretamente à produção e distribuição de bens e serviços, mas, à manutenção das estratégias privadas de acumulação.

Nesse sentido e considerando-se o desenvolvimento da moeda fiduciária, os padrões monetários nacionalmente constituídos apresentam, no plano internacional, certa hierarquia que reflete, em última instância, o estado de convenções dos agentes econômicos acerca do poder econômico e político do Estado emissor da moeda em análise. Assim, não seria razoável imaginar que os detentores privados da riqueza passariam a tratar o Real em um patamar idêntico, por exemplo, ao dólar norte-americano. Tais diferenças qualitativas tenderiam a emergir como uma força destrutiva nos momentos de contração cíclica dos mercados financeiros, fenômeno universalmente reconhecido, mesmo por aqueles que trabalham a partir da hipótese de que os mercados são eficientes. Em decorrência dessa linha de argumentação, os críticos de Arida defendem que o Real permaneça "parcialmente conversível" e o Brasil adote uma estratégia de gestão dos fluxos financeiros internacionais mais cautelosa, com a (re)introdução de controles seletivos na conta capital, acúmulo de reservas internacionais, ampliação dos requisitos de operação nos mercados de derivativos de câmbio etc.

Em paralelo às críticas teóricas, vêm sendo realizados exercícios econométricos para avaliar em que medida a abertura financeira no Brasil foi capaz de afetar a taxa de juros no sentido sugerido por Arida, ou mesmo se teria contribuído para a aceleração do crescimento econômico (Ono et al., 2004; Oreiro; Paula; Silva, 2004; Pires, 2004). Tais estudos têm utilizados, como medida de abertura financeira, o índice construído por Soihet (2002) para o período 19902000. Os resultados apresentados seguem a tendência mais geral dos estudos internacionais, com os quais não se estabelece uma relação causal robusta entre liberalização financeira e crescimento econômico. Da mesma forma, não se estabeleceu uma comprovação da hipótese de Arida de que uma maior abertura da conta capital (e/ou maior conversibilidade da moeda nacional) teria sido capaz de reduzir a taxa de juros. Para além do debate acadêmico, o Banco Central consolidou suas práticas regulatórias em 2005, avançando, ainda mais, no caminho da liberalização financeira (Sicsú, 2007). Ademais, em agosto de 2006, demandas do setor privado, especialmente, a FIESP e o CNI, foram convertidas em texto legal alterando muito o arcabouço legal que regula o mercado de câmbio, flexibilizando, sobretudo, a cobertura cambial das exportações do País. Nessa mesma linha, espera-se, para breve, uma nova rodada de flexibilização na legislação vigente, em particular, no que se refere ao controle e registro dos fluxos de capitais estrangeiros, através do afastamento da Lei 4.131 de 1962.

O esforço empírico, aqui, empreendido vem somar-se às iniciativas anteriores que buscam compreender os vínculos entre a abertura financeira e o desempenho macroeconômico nos países em desenvolvimento em geral e, no 
Brasil, em particular. Procurou-se contribuir atualizando as evidências e aplicando novos testes, com indicadores alternativos para mensurar a abertura financeira brasileira. Há, ainda, um largo espaço de pesquisa a ser preenchido, com destaque para a construção de novos indicadores de conversibilidade da conta capital, ampliação do escopo da análise das variáveis macroeconômicas, avaliação das novas regras de regulação do mercado cambial, estudo dos aspectos teóricos da gestão da moeda no contexto da globalização financeira, ressaltando-se que existem várias questões controvertidas no tratamento empírico da liberalização financeira. Ainda assim, é importante observar o fato de que os defensores da conversibilidade plena do Real baseiam-se mais em argumentos teóricos colocados a priori do que em sólidas evidências empíricas. Retornando à reflexão de Bhagwati (1998), é preciso que se aponte enfaticamente, com base em outras experiências e em sólidas evidências empíricas, um balanço menos subjetivo sobre os custos e benefícios da liberalização financeira. É importante aprofundar as investigações sobre o caso concreto do Brasil. Deve-se verificar se a conversibilidade da conta capital nos termos, hoje, praticada (e com seus possíveis aprofundamentos) constitui-se na melhor via para compatibilizar os objetivos de estabilidade e crescimento, considerando-se o estágio atual de desenvolvimento econômico e institucional do País. Nesse sentido, as evidências, aqui, colocadas vão ao encontro das análises teóricas e empíricas de autores que afirmam ser necessário ajustar o processo de integração da economia brasileira à economia internacional a partir de uma perspectiva centrada no desenvolvimento nacional e reconhecer o caráter potencialmente instável do ambiente de finanças globalizadas e desregulamentadas. Assim, nos termos do debate recente sobre o grau desejado de abertura financeira para o País, tanto a análise empírica quanto a apreciação das mudanças regulatórias recentes colocam o presente trabalho em linha com a percepção de Belluzzo e Carneiro (2004); Ferrari et al. (2005); Oreiro, Paula e Silva (2004); Freitas e Prates (2001); Ono et al. (2004); Pires (2004); Sicsú (2007) dentre outros.

É bem verdade que, desde 2003, a convergência de fatores excepcionalmente favoráveis para a conjuntura internacional, tais como elevado crescimento da renda e do comércio, melhoria dos termos de intercâmbio entre os países periféricos, elevada liquidez e taxas baixas de juros nos mercados financeiros, tem conduzido a um expressivo aumento na demanda por ativos emitidos nos mercados emergentes. Vive-se um novo ciclo de euforia nos mercados globalizados e desregulamentados, sancionado por generalizada melhoria da solvência fiscal e externa dos países em desenvolvimento que, na segunda metade dos anos 1990, experimentaram uma sucessão de crises financeiras. O Brasil, também, não é uma exceção nesse movimento mais recente. Novas pesquisas deverão ser realizadas para avaliar em que medida o ambiente favorável em curso representa um ganho defasado no tempo do processo de 
liberalização financeira ou se é a confirmação da dinâmica sugerida pelo FMI dos ciclos financeiros "in-out" ou "feast or famine".

\section{Referências bibliográficas}

ANDIMA. CMN flexibiliza operações de hedge no exterior. 2005. Disponível em: www.andima.com.br. Acesso em: 6 set. 2005.

ARIDA, P. Por uma moeda plenamente conversível. Revista de Economia Política, v. 23, n. 3, p. 151-154, jul./set. 2003a.

. Ainda a conversibilidade. Revista de Economia Política, v. 23, n. 3, p.135142, jul./set. 2003b.

Aspectos macroeconômicos da conversibilidade: uma discussão do caso brasileiro. 2004. Disponível em: www.iepecdg.com. Acesso em: 3 dez. 2005.

; BACHA, E.; LARA-RESENDE. A. High interest rates in Brazil: conjectures on the jurisdictional uncertainty. 2003. Disponível em: www.iepecdg.com. Acesso em: 3 dez. 2005.

ARIYOSHI, Akira; HABERMEIER, K.; LAURENS, B.; OTKER-ROBE, I.; CANALESKRILJENKO, J. I.; KIRILENKO, A. Capital controls: country experiences with their use and liberalization. Washington, DC: IMF, 2000. (IMF Occasional Paper, n. 190).

BASTOS, P. P.; BIANCARELI, A.; DEOS, S. Controle de capitais e reformas liberais: uma comparação internacional. Economia e Sociedade, Campinas, v. 15, n. 3 (28), p. 545576, dez. 2006.

BEKAERT, G.; HARVEY, C.; LUNDBLAD, C. Does financial liberalization spur growth? Journal of Financial Economics, v. 77, n. 1, p. 3-55, 2005.

BELLUZZO, L. G.; CARNEIRO, R. O mito da conversibilidade. Revista de Economia Política, v. 24, n. 2 (94), abr./jun. 2004.

BHAGWATI, Jagdish. The capital myth: the difference between trade in widgets and trade in dollars. Foreign Affairs, 77, p. 7-12, 1998.

CARDOSO, E.; GOLDFAJN, I. Capital flows to Brazil: the endogeneity of capital controls. Washington, DC: IMF, 1997. (IMF Working Paper, n. 115).

CASTRO; BARROS; SOBRAL; GOMES Advogados. Relatório de Junho/2005. Newsletter, jun. 2005. Disponível em: http://www.cbsg.com.br/pdf publicacoes/ newsletter CBSG no2.pdf.

EDISON, H. J.; KLEIN, M. W.; RICCI, L.; SLOK, T. Capital account liberalization and economic performance: survey and synthesis. Cambridge, Mass.: National Bureau of Economic Research, Aug. 2002. (NBER Working Paper, n. 9100).

; WARNOCK, F. A simple measure of the intensity of capital controls. Journal of Empirical Finance, v. 10, n. 1-2, p 81-103, 2003.

EICHENGREEN, B.; LEBLANG, D. Capital account liberalization and growth: was Mr. Mahathir right? Cambridge, Mass.: National Bureau of Economic Research, Dec. 2002. (NBER Working Paper Series, n. 9427). 
ENDERS, W. Applied econometric time series. New York: John Wiley e Sons, Inc., 2004.

FERRARI FILHO, F.; JAYME JR., F.; LIMA, G. T.; OREIRO, J. L. PAULA, L. F. Uma avaliação crítica da proposta de conversibilidade plena do Real. Revista de Economia Política, v. 25, n. 1, p. 133-151, jan./mar. 2005.

FRANCO, G. Pequena história do câmbio no Brasil. 2000. Disponível em: www.econ.pucrio.br/gfranco/a60.htm. Acesso em: 13 jan. 2005.

FREITAS, M. C. P.; PRATES, D. M. A abertura financeira no governo FHC: impactos e conseqüências. Economia e Sociedade, Campinas, v.17, p. 81-111, 2001.

GONÇALVES, F., HOLLAND, M.; SPACOV, A. D. Can jurisdictional uncertainty and capital controls explain the high level of real interest rates in Brazil? Evidence from panel data. Revista Brasileira de. Economia, v. 61, n. 1, p. 49-75, jan./mar. 2007.

GRANGER, C. W. J.; HUANG, B-N.; YANG, C. W. A bivariate causality between stock price and exchange rates: evidence from recent Asia Flu. San Diego: University of California. Department of Economics, 1998. (Discussion Paper, n. 98/09).

IMF. World Economic Outlook. Washington, DC: International Monetary Fund, Apr. 2006.

KAMINSKY, G.; SCHMUKLER, S. Short-run pain, long-run gain: the effects of financial liberalization. Cambridge, Mass.: National Bureau of Economic Research, 2002. (NBER Working Paper, n. 2912).

KOSE, A.; PRASAD, E.; ROGOFF, K.; WEI, S-J. Financial globalization: a reappraisal. Cambridge, Mass.: National Bureau of Economic Research, 2006. (NBER Working Paper, n. 12484).

MISHKIN, F. The next great globalization: how disadvantaged nations can harness their financial systems to get rich. New Jersey: Princeton University Press, 2006.

MINELLA, A.; GOLDFAJN, I. Capital flows and controls in Brazil: what we have learned? Brasília: NBER, 2005. (Working Paper, n. 11640).

OBSTFELD, M.; TAYLOR, A. Global capital markets: integration, crisis, and growth. Cambridge, UK: Cambridge University Press, 2004.

ONO, F. H.; SILVA, G. J.; PAULA, L. F.; OREIRO, J. L. Conversibilidade da conta de capitais e seus desdobramentos: evidências a partir da experiência recente da economia brasileira e mundial. 2004. Disponível em: http://www.joseluisoreiro.ecn.br. Acesso em: 13 jan. 2005.

OREIRO, J. L.; PAULA, L. F.; SILVA, G. J. Por uma moeda parcialmente conversível: uma crítica a Arida e Bacha. Revista de Economia Política, v. 24, n. 2, p. 223-237, abr./jun. 2004.

PATTERSON, K. An introduction to applied econometrics: a time series approach. Basingstoke, UK: Palgrave, 2000.

PIRES, M. C. C. O efeito da liberalização da conta capital sobre a política fiscal: evidências para o caso brasileiro recente (1995-2000). Brasília: Ipea, dez. 2004. (Texto para Discussão, n. 1.061). 
PRASAD, E.; ROGOFF, K.; WEI, S.; KOSE, M. A. Effects of financial globalization on developing countries: some empirical evidence. Washington, DC: International Monetary Fund, Sept. 2003.

QUINN, D. The correlates of changes in international financial regulation. American Political Science Review, v. 91, n. 3, p. 531-551, 1997.

RODRIK, D. Who needs capital account convertibility? Harvard University, Feb. 1998.

SICSÚ, J. Emprego, juros e câmbio: finanças globais e desemprego. Rio de Janeiro: Campus, 2007.

SOIHET, E. Índice de controle de capitais: uma análise da legislação e dos determinantes do fluxo de capital no Brasil no período 1990-2000. Dissertação (Mestrado)-Escola de Pós-Graduação em Economia, Fundação Getúlio Vargas, Rio de Janeiro, 2002.

STIGLITZ, J.; OCAMPO, J.; SPIEGEL, S.; FFRENCH_DAVIS, R.; NAYYAR, D. Stability with growth: Macroeconomics, liberalization and development. New York: Oxford University Press, 2006.

WORLD BANK Economic growth in the 1990s: learning from a decade of reform. Washington, DC: World Bank, 2005. 


\section{Anexos}

1 - Testes de Raiz Unitária para as séries selecionadas (1994:03-2006:02)

\begin{tabular}{l|c|c|c|c|c|c}
\hline Séries & ADF $^{*}$ & $\mathrm{vc}^{* *}$ & coint $^{* * *}$ & PP $^{*}$ & $\mathrm{vc}^{* *}$ & coint $^{* * *}$ \\
\hline LNICC & $-3.3024(c, t)$ & $-3,51$ & $I(1)$ & $-3,3185(c, t)$ & $-3,51$ & $I(1)$ \\
\hline LNCANOMSA & $-1.3828(c)$ & $-2,92$ & $I(1)$ & $-1,3791(c)$ & -2.92 & $I(1)$ \\
\hline LNPIB & $-3,0523(c, t)$ & $-3,51$ & $I(1)$ & $-3,3008(c, t)$ & $-3,51$ & $I(1)$ \\
\hline TXREALSA & $-3,8418(c, t)$ & $-3,51$ & $I(0)$ & $-3,8007(c, t)$ & $-3,51$ & $I(0)$ \\
\hline IAFSA & $-1,8387(c)$ & $-2,93$ & $I(1)$ & $-3,1686(c, t)$ & $-2,93$ & $I(0)$ \\
\hline
\end{tabular}

ADF: Augmented Dick-Fuller Test ; PP: teste de Phillips-Perron (*) t representa adição de uma tendência determinística na especificação do modelo de caracterização da raiz unitária e c representa adição de uma constante; $(* *)$ valor crítico a $5 \%$ de significância; $(* * *)$ Grau de cointegração. Fonte de dados brutos: Soihet (2000), Banco Central do Brasil, Ipeadata. Cálculos obtidos utilizando o software Eviews 5. Onde: (i) LNICC representa a série do logaritmo do Índice de Controle de Capitais; (ii) LNPIB, o logaritmo do PIB, com dados dessazonalizados; (iii) TXREALSA, a taxa de juros real, dessazonalizada; (iv) LNCANOMSA, a série do logaritmo da taxa de câmbio nominal, com dados dessazonalizados e(v) IAFSA, a série do Índice de Abertura Financeira, dessazonalizada.

\section{2 - Funções Impulso-Resposta (DLNICC, DLNPIB, DTXREALSA, DLNCANOMSA)}

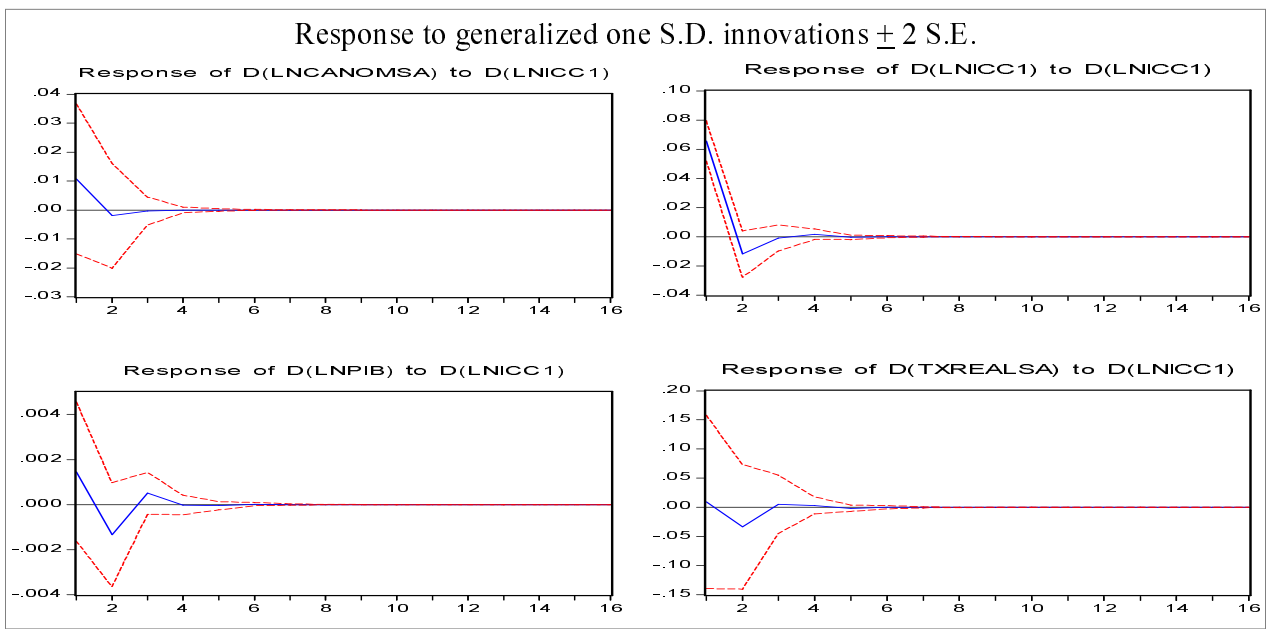


3 - Resultados dos testes de Cointegração bivariada entre as variáveis do VAR (utilizando-se o ICC): Regressão cointegrante: $y_{t}=\beta_{1}+\beta_{2} \cdot x_{t}+e_{t}$

Resultado da estatística-t, $\beta_{1}$ e do $\beta_{2}$ para a relação cointegrante:

\begin{tabular}{|l|c|c|c|}
\hline & $\operatorname{LNICC}\left(\mathrm{x}_{\mathrm{t}}\right)$ & $\operatorname{LNCANOMSA}\left(\mathrm{x}_{\mathrm{t}}\right)$ & $\operatorname{TXREALSA}\left(\mathrm{x}_{\mathrm{t}}\right)$ \\
\hline \multirow{2}{*}{$\operatorname{LNPIB}\left(\mathrm{y}_{\mathrm{t}}\right)$} & $\beta_{1}=4,1489(164,9)$ & $\beta_{1}=4,0220(60,3)$ & Série I $(0)$, não \\
& $\beta_{2}=0,1445(23,7)$ & $\beta_{2}=0,1365(10,8)$ & cointegra \\
\hline \multirow{2}{*}{$\operatorname{LNCANOMSA}\left(\mathrm{y}_{\mathrm{t}}\right)$} & $\beta_{1}=1,7335(8,0)$ & - & Série I $(0)$, não \\
& $\beta_{2}=0,8624(16,4)$ & - & cointegra \\
\hline
\end{tabular}

Teste de estacionariedade nos resíduos das equações cointegrantes:

\begin{tabular}{|l|c|c|c|}
\hline Séries dos resíduos das equações* & T-Estatístico & Valores críticos** & SIG*** $^{* *}$ \\
\hline LNPIB $=\mathrm{f}($ LNICC) $(\mathrm{c})(0)$ & $-3,0518$ & $\mathbf{5 \%}=-3,4687$ & NCO \\
\hline LNPIB $=$ f(LNCANOMSA) $(\mathrm{c})(0)$ & $-0,6848$ & $\mathbf{5 \%}=-3,4687$ & NCO \\
\hline LNCANOMSA = f(LNICC) (c) $(0)$ & $-1,4662$ & $\mathbf{5 \%}=-3,4687$ & NCO \\
\hline
\end{tabular}

(*) o resíduo estimado pela equação (1) c representa adição de uma constante na especificação do modelo de caracterização da raiz unitária. Os valores entre parênteses caracterizam o número de diferenças defasadas utilizadas na equação de regressão. (**) valores críticos tabelados para o teste de cointegração a partir de MacKinnon's (Patterson, 2000, p. 372) CO - não rejeita a hipótese de estacionariedade dos resíduos (as séries são cointegradas). NCO - rejeita a hipótese de estacionariedade dos resíduos (as séries não são cointegradas).

\section{4 - Testes de Causalidade de Granger (utilizando-se o ICC)}

Pairwise Granger Causality Tests

Date: 04/14/08 Time: 10:33

Sample: 1994Q3 2006Q2

Lags: 1

\begin{tabular}{lccc}
\hline Null Hypothesis: & Obs & F-Statistic & Probability \\
\hline DLNPIB does not Granger Cause DLNICC1 & 46 & 14.3892 & 0.00046 \\
\hline DLNICC1 does not Granger Cause DLNPIB & & 2.37190 & 0.13086 \\
\hline DTXREALSA does not Granger Cause DLNICC1 & 46 & 0.41177 & 0.52448 \\
\hline DLNICC1 does not Granger Cause DTXREALSA & & 1.15775 & 0.28793 \\
\hline DLNCANOMSA does not Granger Cause DLNICC1 & 46 & 0.03546 & 0.85152 \\
\hline DLNICC1 does not Granger Cause DLNCANOMSA & & 0.07497 & 0.78555 \\
\hline DTXREALSA does not Granger Cause DLNPIB & 46 & 4.11568 & 0.04871 \\
\hline DLNPIB does not Granger Cause DTXREALSA & & 2.36922 & 0.13108 \\
\hline DLNCANOMSA does not Granger Cause DLNPIB & 46 & 0.04856 & 0.82663 \\
\hline DLNPIB does not Granger Cause DLNCANOMSA & & 0.23313 & 0.63166 \\
\hline DLNCANOMSA does not Granger Cause DTXREALSA & 46 & 2.81842 & 0.10044 \\
\hline DTXREALSA does not Granger Cause DLNCANOMSA & & 1.14669 & 0.29022 \\
\hline
\end{tabular}


5 - Análise de Decomposição de Variância (utilizando-se o ICC)

\begin{tabular}{c|c|c|c|c|c}
\hline \multicolumn{7}{c}{ Variance Decomposition of D(LNCANOMSA): } \\
\hline Period & S.E. & D(LNCANOMSA) & D(LNICC1) & D(LNPIB) & D(TXREALSA) \\
\hline 1 & 0.088181 & 70.32337 & 2.461564 & 2.602546 & 24.61252 \\
\hline 5 & 0.091203 & 71.01951 & 2.311556 & 3.244040 & 23.42489 \\
\hline 10 & 0.091203 & 71.01951 & 2.311556 & 3.244041 & 23.42489 \\
\hline 16 & 0.091203 & 71.01951 & 2.311556 & 3.244041 & 23.42489 \\
\hline Period & S.E. & D(LNCANOMSA) & D(LNICC1) & D(LNPIB) & D(TXREALSA) \\
\hline 1 & 0.065753 & 0.000000 & 97.71179 & 2.253378 & 0.034834 \\
\hline 5 & 0.075160 & 0.607850 & 79.41220 & 16.25240 & 3.727547 \\
\hline 10 & 0.075161 & 0.608800 & 79.40945 & 16.25318 & 3.728572 \\
\hline 16 & 0.075161 & 0.608800 & 79.40945 & 16.25318 & 3.728572 \\
\hline \multicolumn{7}{|c|}{ Variance Decomposition of D(LNICC1): } \\
\hline Period & S.E. & D(LNCANOMSA) & D(LNICC1) & D(LNPIB) & D(TXREALSA) \\
\hline 1 & 0.010527 & 0.000000 & 0.000000 & 92.03396 & 7.966041 \\
\hline 5 & 0.011337 & 3.307635 & 1.729206 & 80.20280 & 14.76036 \\
\hline 10 & 0.011337 & 3.307647 & 1.729692 & 80.20196 & 14.76071 \\
\hline 16 & 0.011337 & 3.307647 & 1.729692 & 80.20196 & 14.76071 \\
\hline \multicolumn{7}{|c|}{ Variance Decomposition of D(TXREALSA): } \\
\hline 10 & 0.529996 & 3.097248 & 0.776656 & 2.962620 & 93.16348 \\
\hline 1 & 0.504538 & 0.000000 & 0.000000 & 0.000000 & 100.0000 \\
\hline 6 & 0.529996 & 3.097229 & 0.776650 & 2.962617 & 93.16350 \\
\hline Cholesky Ordering: D(TXREALSA) D(LNPIB) D(LNICC1) D(LNCANOMSA) \\
\hline
\end{tabular}

6 - Rubricas do balanço de pagamentos componentes do IAF

Conta capital

2630 - Transferências unilaterais de capital (receita); 2631 - Transferências unilaterais de capital (despesa)

Conta financeira

Investimento direto

8081 - Investimento estrangeiro direto - IED (crédito); 8082 - Investimento estrangeiro direto - IED (débito);

8073 - Investimento brasileiro direto - IBD (crédito); 8074 - Investimento brasileiro direto - IBD (débito)

Investimento em carteira;

8100 - Investimento estrangeiro em carteira - IEC (crédito); 8101 - Investimento. estrangeiro em carteira - IEC (débito);

2659 - IBC - ações e títulos de renda fixa - total (aplicação);

2661 - IBC - ações de companhias estrangeiras exclusive BDR (aplicação);

2664 - IBC - ações e títulos de renda fixa - total (retorno);

2666 - IBC - ações de companhias estrangeiras exclusive BDR (retorno).

Continua..

Economia e Sociedade, Campinas, v. 20, n. 1 (41), p. 79-112, abr. 2011. 
Continuação

Derivativos

2687 - Derivativos - ativos (líquido); 2688 - Derivativos - passivos (líquido);

Outros investimentos

2691/2 - Empréstimos e Financiamento LP (débito e crédito); 8128 - Empréstimos e Financiamento CP e LP (líquido);

2694 - Depósitos (líquido); 2697 - OIB - Outros ativos LP (líquido);

2698 - OIB - outros ativos CP (líquido);

2700/01/02/05 - Outros investimentos estrangeiros - créditos comerciais CP e LP (crédito e débito); 2709/10/18/19 - OIE - Financiamentos de governos e organismos multilaterais LP (crédito e débito);

2711/20 - OIE - Financiamento de Importações LP;

2712/13/21, 8152/53/55 - OIE - Outros Investimentos LP (crédito e débito);

2723/24 - Empréstimos e Financiamentos CP (crédito e débito);

8140/41 - OIE - Empréstimos e Financiamentos LP (crédito e débito);

8154/57 - OIE - Financiamento de Agências Governamentais (crédito e débito).

Fonte: BC (2005).

\section{7 - Funções Impulso-Resposta (DIAFSA, DLNPIB, DTXREALSA, DLNCANOMSA)}

Response to generalized one S.D. innovations \pm 2 S.E.
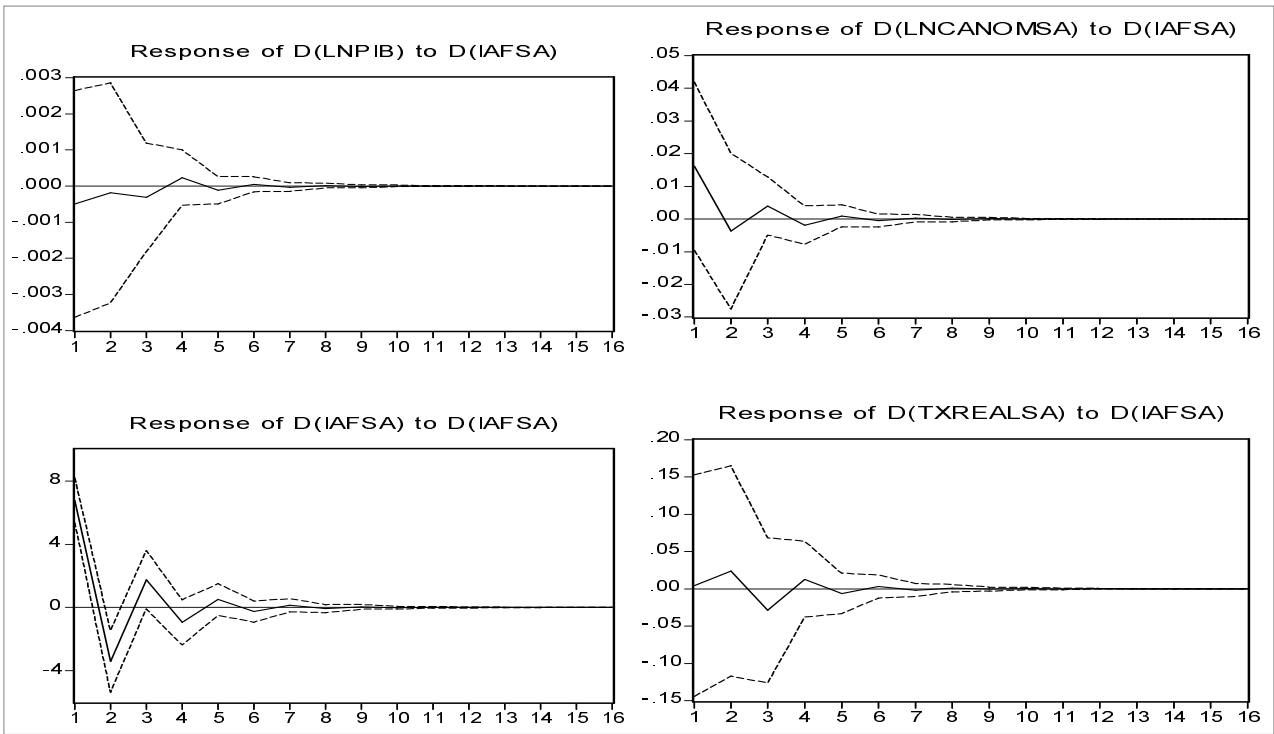
8 - Testes de causalidade de Granger (utilizando o IAF)

\begin{tabular}{|c|c|c|c|}
\hline \multicolumn{4}{|l|}{ Pairwise Granger Causality Tests } \\
\hline \multicolumn{4}{|l|}{ Date: 02/01/07 Time: 02:25 Sample: 1994Q3 2006Q2 Lags: 1} \\
\hline Null Hypothesis: & Obs & F-Statistic & Probability \\
\hline DLNCANOMSA does not Granger Cause DIAFSA & 46 & 0.41041 & 0.52516 \\
\hline DIAFSA does not Granger Cause DLNCANOMSA & & 2.46025 & 0.12409 \\
\hline DLNPIB does not Granger Cause DIAFSA & 46 & 0.03219 & 0.85846 \\
\hline DIAFSA does not Granger Cause DLNPIB & & 0.00087 & 0.97665 \\
\hline DTXREALSA does not Granger Cause DIAFSA & 46 & 1.24489 & 0.27073 \\
\hline DIAFSA does not Granger Cause DTXREALSA & & 0.54117 & 0.46594 \\
\hline DLNPIB does not Granger Cause DLNCANOMSA & 46 & 0.23313 & 0.63166 \\
\hline DLNCANOMSA does not Granger Cause DLNPIB & & 0.04856 & 0.82663 \\
\hline DTXREALSA does not Granger Cause DLNCANOMSA & 46 & 1.14669 & 0.29022 \\
\hline DLNCANOMSA does not Granger Cause DTXREALSA & & 2.81842 & 0.10044 \\
\hline DTXREALSA does not Granger Cause DLNPIB & 46 & 4.11568 & 0.04871 \\
\hline DLNPIB does not Granger Cause DTXREALSA & & 2.36922 & 0.13108 \\
\hline
\end{tabular}

9 - Análise de decomposição de variância (utilizando o IAF)

\begin{tabular}{cccccc}
\hline \multicolumn{5}{c}{ Variance Decomposition of D(LNPIB): } \\
\hline Period & S.E. & D(LNPIB) & D(LNCANOMSA) & D(IAFSA) & D(TXREALSA) \\
1 & 0.010638 & 90.58988 & 2.019548 & 0.019196 & 7.371373 \\
5 & 0.011503 & 77.82405 & 6.777408 & 0.290872 & 15.10767 \\
10 & 0.011503 & 77.82149 & 6.777266 & 0.293626 & 15.10762 \\
16 & 0.011503 & 77.82148 & 6.777266 & 0.293630 & 15.10762 \\
\hline \multicolumn{5}{c}{ Variance Decomposition of D(LNCANOMSA): } \\
\hline Period & S.E. & D(LNPIB) & D(LNCANOMSA) & D(IAFSA) & D(TXREALSA) \\
1 & 0.087981 & 0.000000 & 77.34394 & 0.000000 & 22.65606 \\
5 & 0.090900 & 0.141565 & 77.35455 & 0.981980 & 21.52191 \\
10 & 0.090903 & 0.141645 & 77.35086 & 0.986027 & 21.52147 \\
16 & 0.090903 & 0.141645 & 77.35085 & 0.986033 & 21.52147 \\
\hline \multicolumn{5}{c}{ Variance Decomposition of D(IAFSA): } \\
\hline Period & S.E. & D(LNPIB) & D(LNCANOMSA) & D(IAFSA) & D(TXREALSA) \\
1 & 6.784992 & 0.000000 & 4.580648 & 95.41227 & 0.007079 \\
5 & 8.027469 & 0.214013 & 4.993344 & 91.33894 & 3.453707 \\
10 & 8.034162 & 0.216642 & 4.991293 & 91.32533 & 3.466737 \\
16 & 8.034173 & 0.216646 & 4.991289 & 91.32531 & 3.466759 \\
\hline \multicolumn{5}{c}{ Variance Decomposition of D(TXREALSA): } \\
\hline Period & S.E. & D(LNPIB) & D(LNCANOMSA) & D(IAFSA) & D(TXREALSA) \\
1 & 0.502846 & 0.000000 & 0.000000 & 0.000000 & 100.0000 \\
5 & 0.533625 & 2.211133 & 5.075705 & 1.169817 & 91.54335 \\
10 & 0.533641 & 2.211133 & 5.075485 & 1.174635 & 91.53875 \\
16 & 0.533641 & 2.211133 & 5.075485 & 1.174643 & 91.53874 \\
\hline \multicolumn{5}{c}{ Cholesky Ordering: D(TXREALSA) D(LNCANOMSA) D(IAFSA) D(LNPIB) } \\
\hline \multicolumn{5}{c}{}
\end{tabular}


Cesar Rodrigues van der Laan / André Moreira Cunha / Marcos Tadeu Caputi Lélis

\section{0 - Teste de Estabilidade Estrutural (Chow's Breakpoint Test)}

Teste de Chow com ponto de quebra em 1999Q1 (série em nível)

F-statistic 3.06E-05 Probability

Log likelihood ratio $3.50 \mathrm{E}-05 \quad$ Probability

0.995614

Teste de Chow com ponto de quebra em 1999Q1 ( $1^{\text {a }}$ diferença)

F-statistic

0.123102

Probability

0.995277

Log likelihood ratio

0.128521

Probability

0.727369

0.719971 